\title{
Response of the mesosphere-thermosphere- ionosphere system to global change - CAWSES-II contribution
}

\author{
Jan Laštovička ${ }^{1 *}$, Gufran Beig ${ }^{2}$ and Daniel R Marsh ${ }^{3}$
}

\begin{abstract}
Long-term trends in the mesosphere, thermosphere, and ionosphere are areas of research of increasing importance both because they are sensitive indicators of climatic change and because they affect satellite-based technologies which are increasingly important to modern life. Their study was an important part of CAWSES-II project, as they were a topic of Task Group 2 (TG-2) 'How Will Geospace Respond to Changing Climate'. Three individual projects of TG-2 were focused on important problems in trend investigations. Significant progress was reached in several areas such as understanding and quantifying the role of stratospheric ozone changes in trends in the upper atmosphere, reaching reasonable agreement between observed and simulated trends in mesospheric temperatures and polar mesospheric clouds, or understanding of why the thermospheric density trends are much stronger under solar cycle minimum conditions. The TG-2 progress that is reviewed in this paper together with some results reached outside CAWSES-II so as to have the full context of progress in trends in the upper atmosphere and ionosphere.
\end{abstract}

Keywords: Mesosphere; Thermosphere; lonosphere; Long-term trends; Climatic change

\section{Review \\ Introduction}

The anthropogenic emissions of greenhouse gases carbon dioxide $\left(\mathrm{CO}_{2}\right)$, methane $\left(\mathrm{CH}_{4}\right)$, and nitrous oxide $\left(\mathrm{N}_{2} \mathrm{O}\right)$ influence the troposphere, weather, and particularly climate. They appear to be the primary driver of a significant increase of surface temperature in recent decades, thus affecting directly our lives. Another anthropogenic pollutant of the atmosphere, ozone depleting substances (ODSs), is responsible for the depletion of the Earth's stratospheric ozone layer, particularly over the Antarctica, in the form of the spring ozone hole. Both greenhouse gases and ODS thus affect the environment and can adversely influence human health. However, these polluting substances affect not only the troposphere and stratosphere but also the upper atmosphere, including the mesosphere (approximately 50 to $90 \mathrm{~km}$ ), the thermosphere (approximately 90 to $1000 \mathrm{~km}$ ), and the ionosphere, which is embedded in the upper atmosphere (e.g., Rishbeth and Roble 1992;

\footnotetext{
* Correspondence: jla@ufa.cas.cz

${ }^{1}$ Institute of Atmospheric Physics ASCR, Bocni II, Prague 14131, Czech Republic

Full list of author information is available at the end of the article
}

Laštovička et al. 2012). The thermosphere is the operating environment of many satellites, including the International Space Station, and thousands of pieces of dangerous space debris, the orbital lifetime of which depends on long-term changes of thermospheric density. Propagation of Global Positioning System (GPS) signals and radio communications are affected by the ionosphere. Thus, anthropogenic changes of the high-altitude regions, thermosphere, and ionosphere can also affect satellite-based technologies which are increasingly important to modern life. As with global change near the Earth's surface, the challenge faced by the upper atmosphere climate scientists is to detect long-term trends and understand their primary causes, so that society can mitigate against potential harmful changes.

The approximately $0.85^{\circ} \mathrm{C}$ increase in global surface air temperature since 1880 (IPCC 2013) has been attributed predominantly to the increasing atmospheric concentration of greenhouse gases. However, the greenhouse gas increase has an opposite, cooling effect in the upper atmosphere. Greenhouse gases in the troposphere are optically thick to outgoing long-wave (infrared) radiation, which they absorb. Then they emit radiation, corresponding to local 
temperature, and part of this emission goes back to the surface to produce the heating effect. In contrast, greenhouse gases in the much lower density upper atmosphere are optically thin to outgoing infrared radiation. In situ collisional excitation results in atmospheric thermal energy easily lost to space via outgoing infrared radiation causing infrared radiative cooling, while the absorption of radiation emanating from the lower atmosphere plays only a secondary role in the energy balance. The net result is that the radiatively active greenhouse gases act as cooling agents, and their increasing concentrations enhance the cooling effect in the upper atmosphere. This effect of greenhouse gases may be called 'greenhouse cooling' (Cicerone 1990).

The global atmosphere is close to a hydrostatic equilibrium, which means that the height of a given pressure surface is determined by the average atmospheric temperature below. The cooling is expected to result in thermal contraction of the upper atmosphere, and we may expect a significant decline in thermospheric density at fixed heights, which is observed in long-term satellite drag data (e.g., Emmert et al. 2008). Downward displacement of ionospheric layers should accompany this contraction, and this has also been observed (e.g., Laštovička et al. 2012). The cooling also affects chemical reaction rates and, thus, the chemistry of minor constituents, resulting in further changes to the ionosphere.

The combination of the lower atmosphere heating and the upper atmosphere cooling is supported by a much stronger greenhouse effect that is observed on Venus where the $96 \%$ concentration of carbon dioxide in the atmosphere and a more dense atmosphere result in a troposphere that is more than twice as warm as the Earth's troposphere and a thermosphere that is 4 to 5 times colder than the Earth's thermosphere (e.g., Bougher and Roble 1991). While the Earth's troposphere is much colder than the thermosphere, the Venusian troposphere is substantially warmer than the thermosphere.

Long-term changes in the upper atmosphere and ionosphere have been of interest since the pioneering study of Roble and Dickinson (1989). They suggested that global cooling will occur in the upper atmosphere in conjunction with global warming in the troposphere due to long-term increase of greenhouse gas concentrations, particularly $\mathrm{CO}_{2}$. Modeling studies by Rishbeth (1990) and Rishbeth and Roble (1992) broadened these results to the thermosphere-ionosphere system. Investigation of long-term changes in the upper atmosphere has become a significant topic in global change investigation, and many results have been published in the last more than 20 years (e.g., review by Laštovička et al. 2012 and references herein).

After years of rather chaotic and partly controversial observational results, a sufficient amount of information made it possible to create a first scenario of global change in the mesosphere, thermosphere, and ionosphere by an international team (Laštovička et al. 2006a, 2008a). Summarized in Figure 1, it reveals a cooling in the stratosphere, mesosphere, and thermosphere with no trend in the coolest part of the atmosphere, the mesopause, and some changes in the electron density profile in various ionospheric layers. Its main feature is cooling of the upper atmosphere, which results in thermal contraction of the mesosphere and thermosphere and changes in the ionosphere through changes in chemical composition and recombination rates. However, at that time, results concerning some variables were not consistent with the trend scenario and many variables were missing. This scenario has been continuously improved and updated (e.g., see reviews or progress reports by Qian et al. 2011; Laštovička et al. 2012; Danilov 2012; Laštovička 2013a). At present, the scenario is formed by essentially mutually consistent trends in the mesospheric temperature, electron concentration in the lower ionosphere, E region, F1 region, and F2 region; height of maximum electron concentration in the $\mathrm{E}$ region and F2 region; the thermospheric neutral density; F-region ion; and electron temperatures. These trends are basically mutually consistent and qualitatively agree with model simulations that show that they are the consequences of the enhanced greenhouse gases. However, there are also some problems with these trends. For example, ion temperature trends above approximately $350 \mathrm{~km}$ in middle latitudes are rather opposite to those at high latitudes (Laštovička 2013a). Electron temperature trends are still very preliminary. There are some discrepancies between electron density trends from different stations, and they seem to depend to some extent on the time of the day (e.g., Qian et al. 2009). Trend information about several quantities is missing or is not reliable.

It is useful to clarify what the term 'trend' means, as its understanding can differ among authors. Most authors use the term trend as a 'long-term trend', i.e., as a long-term tendency of essentially monotonic or quasilinear change, either an increase or decrease of the values of a particular variable with time. If the long-term behavior is substantially unstable on medium timescales, or oscillatory, the term 'long-term change' is usually used. Strictly speaking, trends are often not linear. However, in most cases, the linear trend approximation is sufficient; in other cases, we use the linear approximation to facilitate comparison with trends in other parameters. Ideally, a trend continues to infinity. In reality, a period of quasi-stable trends begins and ends in concrete years/periods, such as the Antarctic ozone hole, which appeared in the late 1970s, that has recently stabilized, and it is expected to disappear in the second half of this century (Eyring et al. 2010). Such behavior may be 


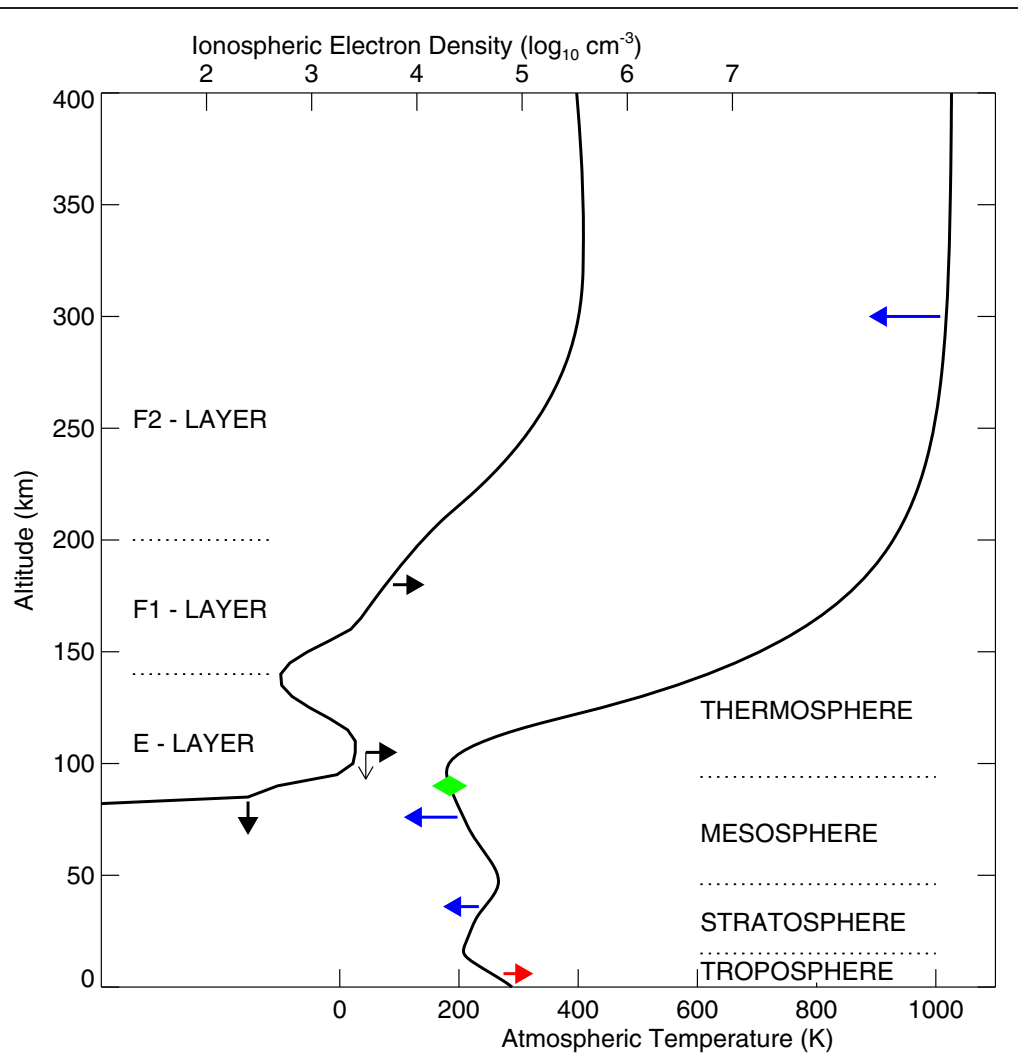

Figure 1 Trends in the Earth's atmosphere. The atmospheric layers are defined by the temperature profile. The ionospheric layers are defined by the electron density profile (midnight at equator). Arrows indicate the direction of change. Red - warming, blue - cooling, green - no change of temperature, black - changes in electron density (horizontal) and heights of ionospheric layers (vertical). After Laštovička et al. (2008a).

characterized by a sophisticated mathematical curve, but it is often approximated by a piecewise linear trend model (Weatherhead et al. 2000; Reinsel et al. 2005), wherein substantially different linear trends are fit to the data within different time intervals. The upper atmosphere and ionosphere linear trends should be understood in such a way, even though for some variables the period of quasi-stable trend may be identical with the period of available data for trend studies, i.e., such trends might appear to be monotonic.

It is also possible to use a slightly different and more formal mathematical approach. A truly linear trend in a time series, by definition, corresponds to the lowest frequencies that are not taken into account in a spectral decomposition. More precisely, quoting Kendall (1973), 'The essential idea of the trend is that it shall be smooth', which is equivalent to a continuous slowly varying change in a time series over long-time scales (Graigmile et al. 2004). Assuming that the trend is not a small temporal part of a major very long-period cycle or due to some temporally-coincident stochastic change, then it is possible to temporally and spectrally decompose the time series to separate the oscillatory and true trend elements using, for instance, the wavelet transform technique.
However, practical application of such an approach has to be made with care, as the trend has a non-infinite period limited by the length of the dataset or by the limited length of the stable trend interval. This is probably the reason why the attempt of a Chilean team to use such an approach in foF2 trend analysis (Laštovička et al. 2006b) was unsuccessful (Laštovička et al. 2008b).

The international SCOSTEP project Climate and Weather of the Sun-Earth System (CAWSES-II), ran in 2009 to 2013. It consisted of several Task Groups (TGs), one of them being TG-2 'How Will Geospace Respond to Changing Climate'. Geospace, here, is understood to be the upper atmosphere (mesosphere and thermosphere) and ionosphere. TG-2 was organized around three projects that aimed to answer three questions:

Project 1. How do changes in tropospheric wave generation and their propagation through a changing atmosphere affect the dynamics of the MLT?

Project 2. By how much is the anthropogenic effect on the ionosphere/thermosphere enhanced during a quiet sun period?

Project 3. Are PMC/NLC frequency and brightness trending due to changes in temperature and water vapor? Do they differ between the hemispheres? 
It should be mentioned that TG-2 also organized or co-organized international scientific meetings. Project 3organized the CAWSES-II workshop on modeling PMC trends. The workshop was held at LASP, University of Colorado, Boulder, USA on 3 to 4 May 2012 with the participation of 35 scientists and students. TG-2 coorganized two IAGA/ICMA/CAWSES workshops 'Long Term Changes and Trends in the Atmosphere' on 15 to 18 June 2010 at NCAR, Boulder, USA and on 11 to 14 September 2012 in Buenos Aires, Argentina. Participation at both workshops was approximately 70 scientists. A special issue of the Journal of Geophysical Research was published from each workshop. Both workshops provided a clear picture of where we are in studying long-term trends in the upper atmosphere and ionosphere and what are the goals for research in the near future.

The aim of this paper is to describe the main findings of each TG-2 project in the context of the general progress in the field of long-term trends in the mesosphere, thermosphere, and ionosphere. In recent years, it became quite clear that there are also other drivers of trends. This is described in the 'Other drivers of longterm trends' section. The 'Are there long-term changes in tropospheric wave generation and their propagation through a changing atmosphere?' and 'Are trends related to upward propagation of atmospheric waves observed in the mesosphere, lower thermosphere and ionosphere (MLTI)?' sections deal with the main results and activities of Project 1. Findings of Project 2 are in the 'By how much is the anthropogenic effect on the ionosphere/thermosphere enhanced during a quiet sun period?' section and those of Project 3 in the 'Are PMC/ NLC frequency and brightness trending due to changes in temperature and water vapor?' section. The 'Important results reached outside of the CAWSES-II project TG-2' section deals with important results reached outside of these three projects; most of them were reached by scientists participating in TG-2 of CAWSES-II. The paper is closed by a brief 'Conclusions' section, which includes ideas for future investigations.

\section{Other drivers of long-term trends}

In recent years, it became increasingly clear that rising concentrations of greenhouse gases are the main, but not the only, driver of global change in the upper atmosphere (e.g., Laštovička et al. 2012). In the stratosphere, mesosphere, lower thermosphere, and related part of the ionosphere, some role is played by anthropogenic changes of the ozone layer (already mentioned in the introduction) and increasing concentration of water vapor. In the thermosphere and ionosphere, long-term variations of geomagnetic activity and secular changes of the Earth's magnetic field (both important particularly for the F2 region ionosphere) play a role. Due to correction for the solar cycle effect when calculating the trends, the direct impact of long-term changes of solar activity is largely removed. However, an indirect effect remains, at least in thermospheric density (see 'By how much is the anthropogenic effect on the ionosphere/ thermosphere enhanced during a quiet sun period?' section). The poorly known trends in atmospheric circulation and particularly in atmospheric wave activity with predominantly tropospheric sources (one of potential trend drivers) are the key open question in the upper atmosphere and ionosphere trends. Temporal and spatial changes of long-term trends in the upper atmosphere and ionosphere are inevitable (e.g., Laštovička et al. 2012) because trends of some of these drivers change principally with time (e.g., ozone or geomagnetic activity) or location (e.g., Earth's magnetic field). Long-term changes in the relative role of greenhouse gases versus solar/geomagnetic activity in long-term trends in the atmosphere-ionosphere system are documented by Laštovička (2005). The longterm instability of trends is a problem in their investigation, simulation and interpretation, and points to the necessity of continuous monitoring and investigation of such trends.

An important driver of trends is the long-term change in geomagnetic activity. An increase of geomagnetic activity was observed throughout the twentieth century (e.g., Clilverd et al. 1998; Martini and Mursula, 2008) followed by a drop to rather low level at present (particularly 2008 to 2010). Geomagnetic activity might even be a dominant cause of ionospheric trends in the past. Bremer et al. (2009) reported the dominant role of the long-term change of geomagnetic activity on ionospheric trends around 1970 in the E region, in the mid-1990s in the F1 region, and around 2000 in the F2 region. Thus, it appears that at present, the longterm changes in geomagnetic activity are not the main driver of trends in any variable, contrary to the past, when they might have controlled ionospheric trends.

A regionally important driver is the secular change of the main magnetic field of the Earth. Its effect is insignificant in most regions but in the equatorial to southern mid-latitude western Atlantic Ocean and in related part of the South America it seems to play a substantial role in trends in hmF2 and foF2 (e.g., Cnossen and Richmond 2008, 2013). This effect is dominated by changes of inclination and to some extent also declination of the Earth's magnetic field, but changes of field strength cannot be neglected, as well.

In the mesosphere and lower thermosphere, important additional drivers appear to be stratospheric ozone, changes in $\mathrm{CH}_{4}$, and mesospheric water vapor concentration. An important but unclear role is played by changes of the MLT region dynamics, including atmospheric wave 
activity. Figure 2 shows the results of model calculations of $\mathrm{O}_{3}$ depletion (halved), $\mathrm{H}_{2} \mathrm{O}$ increase (doubled), and $\mathrm{CH}_{4}$ increase (doubled) effect on mesospheric and thermospheric temperature and neutral density (Qian et al. 2011). Model changes of $\mathrm{O}_{3}, \mathrm{H}_{2} \mathrm{O}$, and $\mathrm{CH}_{4}$ are much higher than the observed changes. Nevertheless, Figure 2 illustrates that effect of these trace gases at mesospheric and lower thermospheric altitudes cannot be neglected. Model calculations by Qian et al. (2013), with realistic values of concentrations of radiatively active trace gases in the middle atmosphere, confirm the dominant role of $\mathrm{CO}_{2}$ in the thermosphere with minor but, even at $400 \mathrm{~km}$, not quite negligible influence of middle atmospheric ozone, $\mathrm{CH}_{4}$, and water vapor. Ionospheric evidence from the $\mathrm{D}$ and $\mathrm{E}$ regions supports the role of stratospheric ozone in long-term trends (e.g., Laštovička et al. 2012 and references herein).

An increase in mesospheric water vapor is expected from the $150 \%$ increase in $\mathrm{CH}_{4}$ over preindustrial levels (IPCC 2013), and that water is produced from $\mathrm{CH}_{4}$ oxidation in the middle atmosphere. However, observations show a recent drop in the stratospheric water vapor concentration in 2001 and again in 2008 (e.g., Solomon et al. 2010a), suggesting trends in the mesospheric water vapor concentration are far from linear. The role of stratospheric ozone in long-term trends in the MLTI region is crucial but it is treated in 'Are trends related to upward propagation of atmospheric waves observed in the mesosphere, lower thermosphere and ionosphere (MLTI)?' section.

Are there long-term changes in tropospheric wave generation and their propagation through a changing atmosphere?

It is very likely that trends in the lower atmosphere have an influence on the upper atmosphere via dynamical coupling through upward propagating waves. There is modeling evidence that fluxes of waves entering the mesosphere, lower thermosphere, and ionosphere (MLTI) have changed and will continue to change. Trends in the stratospheric Brewer-Dobson circulation were analyzed by Hardiman et al. (2013) in a number of historical and future simulations using 'high-top' climate models. They found annual mean tropical upwelling increased in the models, and that the width of upwelling region decreased below the $20 \mathrm{hPa}$ pressure level and increased above that level. This is believed to be caused by changes in the propagation of planetary and gravity waves. Such changes in the tropical upwelling could affect the timing of the quasi-biennial oscillation and its imprint in the mesosphere (Ratnam et al. 2008), and also the speed of the tropical water vapor tape recorder. However, age of air data does not confirm a simple pattern of reduction of age of air as a consequence of the Brewer-Dobson circulation intensification (Engel et al. 2009; Stiller et al. 2012). There is not one positive or negative linear variation of age of air over the globe (Stiller et al. 2012). There are hemispheric differences and seasonal differences in the long-term behavior of age of air. A different long-term behavior of the lower and upper branches of the Brewer-Dobson circulation is quite possible.

New modeling studies using the Whole Atmospheric Community Climate Model (WACCM) (Smith et al. 2010) indicate a significant role of the development of the Antarctic stratospheric ozone hole in long-term trends in the MLTI region. Dramatic ozone loss in the lower stratosphere results in a temperature decrease in the polar lower stratosphere and a change in the zonal wind distribution. Smith et al. (2011) showed that this change modifies gravity wave propagation into the mesosphere during late spring so that the mesospheric residual mean circulation is weakened by the gravity wave drag. This leads to a reduction in polar ascent rates and thus anomalous adiabatic heating and more than a $4 \mathrm{~K}$ increase in temperature at $80 \mathrm{~km}$ between 1960 and 2006 over the summer pole, and a $6 \mathrm{~K}$ cooling above that level. In contrast, little change was seen over the summer pole in the Northern Hemisphere. The mesospheric warming over
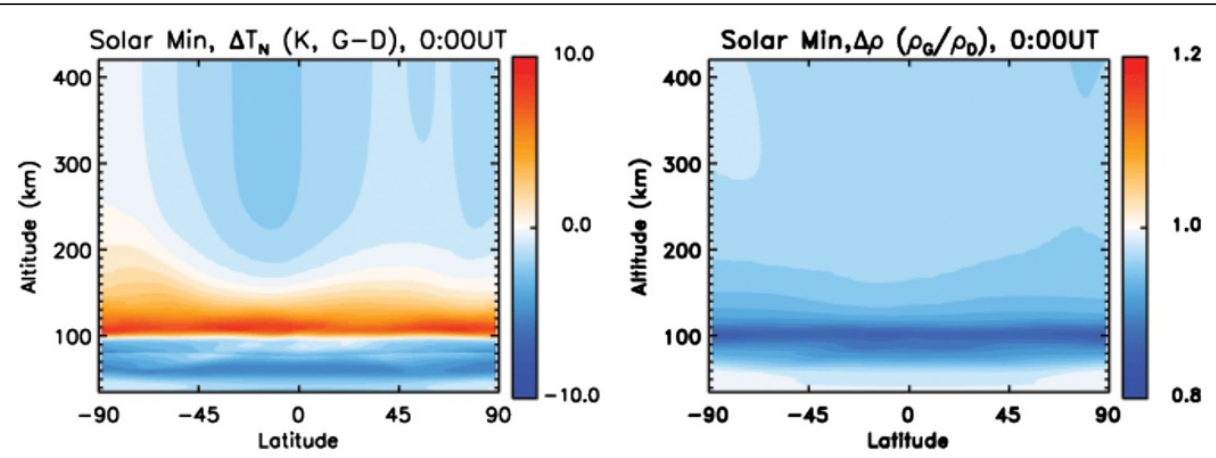

Figure 2 Changes of zonal mean. Changes of zonal mean neutral temperature (left panel) and neutral density (right panel) due to trace gases other than $\mathrm{CO}_{2}$, such as $\mathrm{O}_{3}$ depletion (halved), $\mathrm{H}_{2} \mathrm{O}$ increase (doubled), and $\mathrm{CH}_{4}$ increase (doubled) under solar minimum and geomagnetic quiet conditions, at $0000 \mathrm{LT}$, doubled $\mathrm{CO}_{2}$, simulated by the NCAR TIMEGCM model. After Qian et al. (2011). 
the Antarctic was not present in a simulation in which ODS concentrations were kept constant at pre-ozone-hole levels. This influence of the ozone hole in changing wave propagation into the MLTI was later confirmed in simulations using the Canadian Middle Atmosphere Model (CMAM) (Lossow et al. 2012), although their effect was less pronounced in December in CMAM than WACCM, likely due to too delayed breakup of the polar vortex in WACCM.

Another possible source of medium-to-long-term variability in wave propagation is the 11 year solar cycle. Ern et al. (2013) presented model simulations that suggest a small increase in planetary wave activity during solar maximum. There is also some observational evidence that gravity wave momentum fluxes vary out of phase with the solar cycle in the middle stratosphere (Ern et al. 2011); however, this finding is based on just nine years of data. The role of stratospheric ozone in long-term trends in the MLTI region is crucial, but it is treated in the next section.

\section{Are trends related to upward propagation of atmospheric waves observed in the mesosphere, lower thermosphere, and ionosphere (MLTI)?}

Two quantities, with some long-term data series of observations at MLT heights, are winds and temperatures; therefore, below we summarize trends in these two quantities. However, the problem is that the situations with trends in atmospheric wave activity at MLTI heights is not clear and, unfortunately, there are strong indications that these trends might differ substantially by region.

First results on long-term trends in zonal winds from multi-instrument measurements in the tropical mesosphere over India, 1978 to 2006, for heights approximately 70 to $80 \mathrm{~km}$ (Ratnam et al. 2013) reveal statistically significant negative trends in northern winter (December-March) and in September with maximum trends between 2 and 3 $\mathrm{m} / \mathrm{s} /$ year in late winter (February-March), changing zonal wind from strong eastward during the 1970s to weak westward in recent years. This data series is the compilation of rocket measurements at Thumba, MST (mesospherestratosphere-troposphere) radar measurements at Gadanki and HRDI/UARS satellite measurements in the Indian sector near $10^{\circ} \mathrm{N}$. Simulations with WACCM for $11.5^{\circ} \mathrm{N}$, in winter, qualitatively confirm this result. They provide similar negative trends for all longitudes at heights of 70 to 80 $\mathrm{km}$, whereas trends above $80 \mathrm{~km}$ are longitude dependent (Ratnam et al. 2013). Rao et al. (2012) analyzed approximately 80 to $100 \mathrm{~km}$ altitude winds at low latitudes based on measurements of four medium-frequency radars and three meteor radars. The analyzed data series were 20 years (1990 to 2010) long or shorter at individual stations, i.e., shorter than that used by Ratnam et al. (2013). Rao et al. (2012) did not find trends in the zonal wind; in the meridional wind, they found trends only for some stations, for other station they did not observe any trend.

At middle latitudes, winds at heights of approximately 90 to $95 \mathrm{~km}$ reveal considerable differences in long-term behavior between various regions. Figure 3 illustrates such differences for three stations near $52^{\circ} \mathrm{N}$, Obninsk near Moscow in Russia, Collm in eastern Germany, and Saskatoon in western Canada in winter (December-February). For zonal wind (Figure 3a), each station behaves in its separate way, Obninsk and Saskatoon being almost out-of-phase. The meridional wind reveals more coherent pattern with some long-term (not short-term) similarity for all three stations. The most different pattern is provided by the semidiurnal tidal amplitudes (Figure 3c). Obninsk and Collm display large, out-of-phase changes, whereas no long-term change is seen for Saskatoon. Also, trends in semidiurnal tidal phases reveal evidently different behavior: negative trend in Saskatoon, no trend in Collm, and positive trend in Obninsk. However, such a diverse behavior of mid-latitudinal winds at heights approximately 90 to $95 \mathrm{~km}$ is supported by the results of model simulations by Qian et al. (2011), which reveal a different behavior of trends for different longitudinal regions even as for sign of the trend for zonal wind.

Jacobi and Beig (2013) reported a change of trends in winds in the 1990s. Laštovička et al. (2008a) reported a change of trends in annual prevailing MLT winds at northern higher middle latitudes near 1990. The change of trends around 1990 occurs not only in the MLT annual prevailing wind but also in the lower stratospheric winds at $100 \mathrm{hPa}$ at $50^{\circ} \mathrm{N}$ to $70^{\circ} \mathrm{N}$, in the occurrence frequency of small laminae in ozone profiles in Europe near $50^{\circ} \mathrm{N}$ (Laštovička et al. 2010), and in the stationary planetary wave with zonal wavenumber 1 near $50^{\circ} \mathrm{N}$ (Jacobi et al. 2009). This indicates the possibility of changes in trends in dynamics of the entire northern mid-latitude middle atmosphere.

Little progress on trends in atmospheric wave activity has been reached. This is the key problem of upper atmospheric trends. Jacobi et al. (2012) found regionally significantly different trends in tidal activity based on the mesopause region wind measurements at higher middle latitudes as mentioned above (Figure 3).

Hoffmann et al. (2011) analyzed winds measured at Juliusruh in the northernmost Germany. They observed a positive trend in activity of $\mathrm{T}=3$ to $6 \mathrm{~h}$ gravity waves in the height range of approximately 80 to $90 \mathrm{~km}$ over 1990 to 2010. However, they also mentioned that the gravity wave activity at middle latitudes tends to reveal trends at some stations but no trend at other stations in general agreement with previous results. One possible reason of even locally opposite trends in gravity wave activity at middle latitudes might be the shifts of storm tracks, one of mid-latitude gravity wave sources, towards 


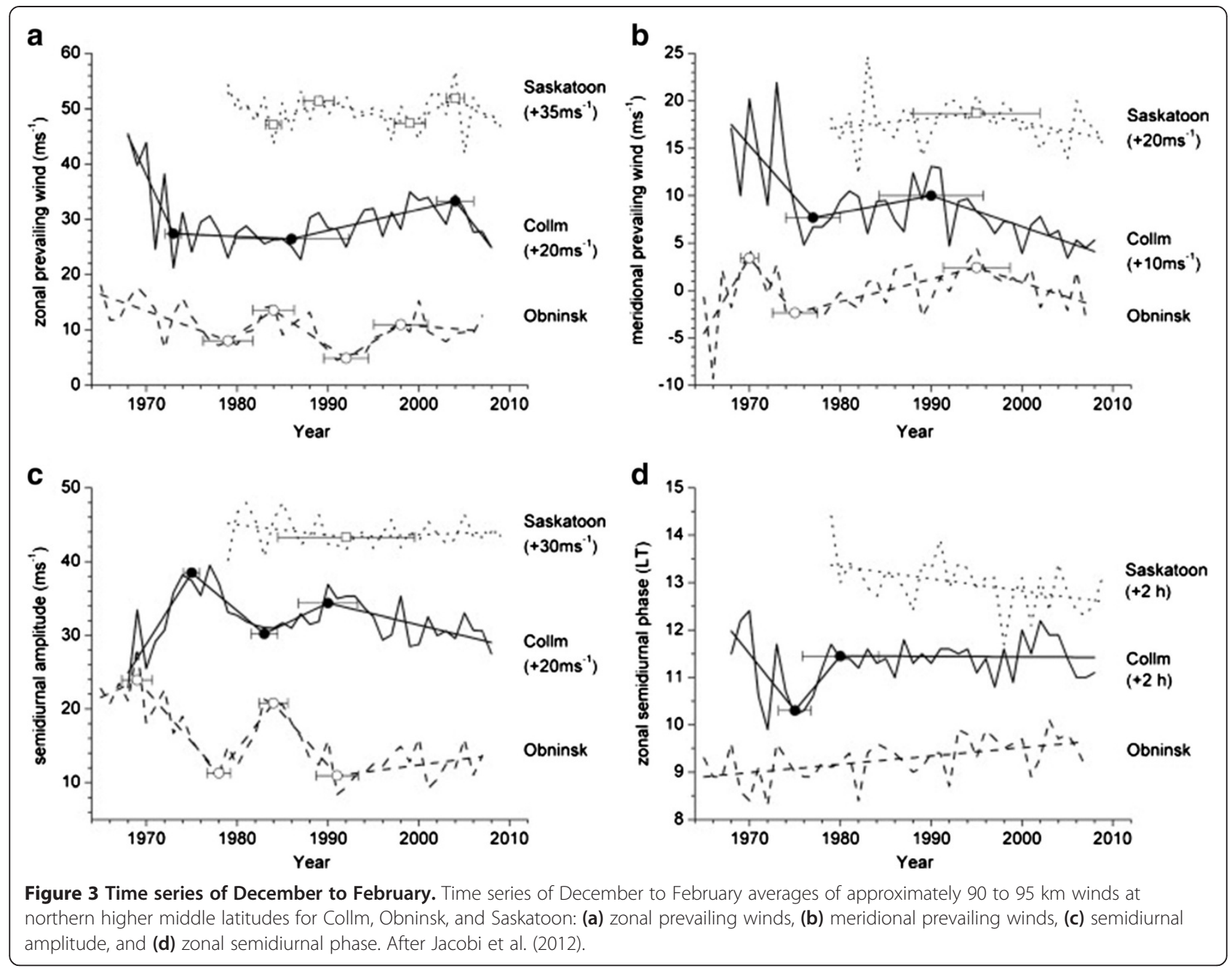

or away from stations. Jacobi and Beig (2013) reported for Juliusruh and Collm (Germany) a positive trend in gravity wave activity in winter and no or a weak negative trend in summer. Tsuda et al. (2013) analyzed data of seven radars in the tropics since the 1990s; they found strengthening of shorter period (20 to $120 \mathrm{~min}$ ) gravity wave activity and no trend for longer periods ( 2 to $10 \mathrm{~h}$ ).

The planetary wave activity trends in the mesopause region over Central Europe are highly variable with period range and season, being generally positive in zonal wind and weaker and negative in meridional wind, and in total wind being in average slightly positive. The trends are more pronounced for short periods $(\mathrm{T}<7$ days) and for summer, whereas at longer periods and in other seasons, they are relatively small and statistically insignificant. Together with scarce information from other regions, they do not provide a clear pattern, as summarized by Laštovička et al. (2012).

Jacobi and Beig (2013) observed a tendency towards an earlier spring transition and a later fall transition in winds. Sonnemann et al. (2012) simulated the impact of dynamics on long-term trends in the MLT region with the LIMA model. They found that in summertime, middle and high latitude MLT region changes in dynamics can counteract the direct impact of anthropogenic increase of greenhouse gases.

Significant progress has been reached since the first review on trends in mesospheric and mesopause region temperatures by Beig et al. (2003). Temperature trend research in the mesopause region (80 to $100 \mathrm{~km}$ ) witnessed dramatic ups and downs during the past decade (Beig 2011). The consensus of the trend community was that the mesopause region was not trending while the upper mesosphere and thermosphere were cooling. However, as the data series has become longer, it is observed that the trend in this region is showing the tendency towards cooling which is change from the earlier perception. The change of trends in stratospheric ozone in the mid-to-second-half of the 1990s had a noticeable impact and resulted in some changes in temperature trends as described in 'Other drivers of long-term trends' section. 
Lübken et al. (2013) pointed out differences between temperature trends at fixed heights and fixed pressure levels. These differences are noticeable even though not principal. Temporal changes of mesospheric temperature are larger at fixed heights than at fixed pressure levels as shown in Figure 4. This figure also illustrates the changes in trend of mesospheric temperatures in relation to changes in ozone trends - steeper negative trend in 1980 to 1995 versus no or slightly positive trend after the mid-1990s. Simulations with model LIMA show that the largest $\mathrm{CO}_{2}$ effect on temperatures is in the middle mesosphere (Lübken et al. 2013). These simulations also reveal thermal shrinking of the mesosphere as a consequence of cooling, which reaches near the height of 80 $\mathrm{km}$ and about $1 \mathrm{~km}$ from 1960 to mid-1990s, which coincides well with the shrinking revealed by the observations of the LF radio wave phase reflection heights in Germany (Lübken et al. 2013).

$\mathrm{OH}$ airglow-derived temperatures (approximately $87 \mathrm{~km}$, mesopause region) above Wuppertal (Germany, $51^{\circ} \mathrm{N}$ ) over 1988 to 2008 reveal a slight but statistically significant, overall cooling trend with substantially different trends in individual months which ranges between 0 and $-0.6 \mathrm{~K} / \mathrm{yr}$, and systematic changes in the shape of seasonal variation (size of summer) of temperature (Offermann et al. 2010). An important finding of this study is an apparent break in trends around 1996, which coincides with the beginning of the recovery phase of stratospheric ozone. She et al. (2009) have carried out an assessment of temperature trends between 85 and $105 \mathrm{~km}$ based on 960 nights of $\mathrm{Na}$ lidar observation over a period of approximately 20 years over Fort Collins $\left(41^{\circ} \mathrm{N}, 105^{\circ} \mathrm{W}\right)$. This study suggests that the impact of volcanic eruptions should be accounted for in trend calculations.
Mlynczak et al. (2010) have analyzed 7 years of observations of the radiative cooling in the thermosphere as observed by the SABER/TIMED. The observed weakening of the equator to the pole gradient in radiative cooling over these 7 years is a strong indication that the large scale thermospheric dynamics have also weakened in that period.

Tropical data over the past 2 decades indicates a cooling trend, but the magnitude is found to be smaller than the earlier results reported mainly from rocketsonde measurements carried out during the late 1960s to early 1990s (Beig 2011). This cooling trend increases with height in the mesosphere and becomes around $3 \mathrm{~K} /$ decade around $70 \mathrm{~km}$, but with an uncertainty of about \pm 1 to $2 \mathrm{~K}$. The cooling trends from the UARS HALOE data set (more than 14 years) are now found to be significant at most latitudes of the middle and lower mesosphere. They range from $-1 \mathrm{~K} /$ decade at low latitudes to about $-3 \mathrm{~K} /$ decade at the middle latitudes (Remsberg 2009). Values of the order of $-1 \mathrm{~K} /$ decade are reasonably consistent with those reported from the lidar measurements at low latitudes (Batista et al. 2009; Sridharan et al. 2009). At middle latitudes, there is reasonable agreement in the middle and upper mesosphere with published values from rocketsonde and lidar measurements of the preceding 2 decades (e.g. Keckhut et al. 1999; She et al. 2009). However, the HALOE trends are smaller in the lower mesosphere probably be due to a reduction in the stratospheric ozone effect compared to earlier periods (Remsberg 2009).

Angot et al. (2012) studied the neutral temperature trends in the height range of 30 to $80 \mathrm{~km}$ above Haute Provence Observatory (OHP, France, $44^{\circ} \mathrm{N}$ ). They found that for comparison with model simulations of the direct effect of anthropogenic changes of radiative forcing, the trends based on background temperatures (excluding
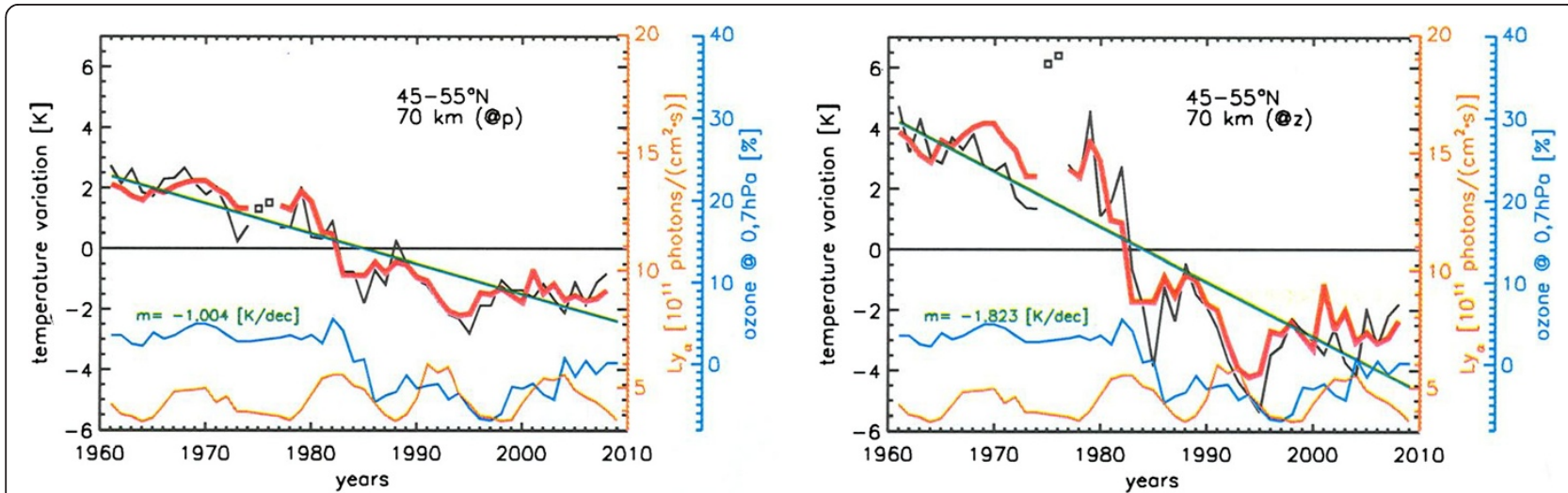

Figure 4 Temperature variations in the latitude band $45^{\circ} \mathbf{N}$ to $55^{\circ} \mathbf{N}$. Temperature variations in the latitude band $45^{\circ} \mathrm{N}$ to $55^{\circ} \mathrm{N}$ on a (left) pressure and (right) geometrical altitude of $70 \mathrm{~km}$. LIMA temperatures (black lines) are compared with a multivariate fit (red lines) consisting of carbon dioxide, ozone, and Ly-a. For comparison, a linear fit over the entire time period is also shown (green line). The orange curve shows the variation of Ly-a and the cyan curve shows the variation of ozone (right axis). The two squares mark temperatures in 1975 and 1976 which are ignored when fitting. After Lübken et al. (2013). 
sudden stratospheric warming periods) should be considered, not total trends.

New observations of temperature trends in the highlatitude mesosphere near 87 to $90 \mathrm{~km}$ above Svalbard $\left(78^{\circ} \mathrm{N}, 16^{\circ} \mathrm{E}\right)$ indicate a changing trend at this location. Older data based on $\mathrm{OH}$-temperature measurements in winter (mostly inside the vortex) by Dyrland and Sigernes (2007) over 1983 to 2005 yield a positive, even though statistically insignificant, trend of $+2 \mathrm{~K} /$ decade. On the other hand, year-round meteor radar measurements over 2002 to 2011 calibrated with satellite Aura data provide a relatively large negative trend of $-4 \pm 2 \mathrm{~K} /$ decade (Hall et al. 2012). More data are necessary to resolve this discrepancy.

The present status of mesopause region temperature trends can be described as follows: (i) the emergence of weak negative trends (a change from the earlier perception of no trend in this region), (ii) an indication of a break in trends at the mesopause region and a signal that trend is likely to strengthen (towards negative) in recent time as compared to the past which seems to be linked to the recovery of stratospheric ozone, (iii) trends in the entire MLT region need not be identical in all the seasons and likely have even monthly variability on long-term scales, and (iv) the importance of dynamics, particularly the role of gravity waves in understanding the variability in mesopause region trends, still remains an issue.

A growing number of model studies during the past decade have advanced to a level where they have started to reproduce a near zero temperature trend with an inclination towards negative trends near the mesopause region. While comparing various long term trend results, it should be noted that the period of measurements for which analysis is reported by various authors are different and it may have a strong bearing in comparisons. The seasonal differences near mesopause region with convincing interpretation still need to be understood sufficiently. The role of dynamics, particularly the role of gravity wave and its breaking, is very important to better understand the temperature trend features reported.

Current knowledge about trends in the ionosphere at heights corresponding to the mesosphere and lower thermosphere has been summarized in a review paper by Laštovička et al. (2012). There was little progress in this area during the CAWSES-II period, but it should be mentioned that the number of open questions here is smaller than it is for trends in the neutral mesosphere and lower thermosphere. Results of Ohya et al. (2011) reveal either no trend or a piecewise linear trend with a change in the second half of the 1990s for VLF tweek atmospherics observed at Kagoshima, Japan over 1976 to 2010. The trend is uncertain due to a large scatter of data.
The impact of trends in atmospheric wave activity on trends in the MLTI region is not yet clear enough, due in part to limited knowledge of trends in wave activity themselves. Still, as stated in the previous section, changes in greenhouse gases and stratospheric ozone are likely to affect wave propagation. Throughout the stratosphere, $\mathrm{O}_{3}$ concentration has been decreasing since about 1979, reaching a minimum in the mid-1990s at northern middle latitudes (e.g., Harris et al. 2008) and later also in other regions. Future ozone changes are likely to affect trends in a way opposite to that in the 1980s. This should result in some modification of trends. In the mesosphere, HALOE trends are weaker than older rocket and lidar-based trends because the ozone effect over the period of HALOE observations was close to zero (Remsberg 2009). Temperature trends in the mesopause region in general changed from no trend to a slight negative trend (Beig 2011). Model results shown in Figure 5 reveal a clear effect of ozone on upper stratospheric and mesospheric temperatures; first, a strengthening of cooling after 1980 and then after the mid1990s, a leveling-off of the trend, if not a slight statistically insignificant heating in the mesosphere. Lübken et al. (2013) estimated the share of $\mathrm{CO}_{2}$ and $\mathrm{O}_{3}$ on mesospheric temperature trends over 1962 to 2009 to be $2: 1$. This all means that the global scenario of trends remains qualitatively the same but changes in ozone trends somewhat changed it quantitatively. The effect of ozone on trends is temporary - it began near 1980 with the beginning of ozone depletion and will disappear after ozone reaches approximately the 1980 ozone level.

\section{By how much is the anthropogenic effect on the ionosphere/thermosphere enhanced during a quiet sun period?}

Long-term trends may be quantitatively different under solar maximum and minimum conditions (an indirect effect of solar cycle), such as in the case of thermospheric density (e.g., Emmert et al. 2008). The reason is the much larger relative role of $\mathrm{CO}_{2}$ radiative cooling compared to NO radiative cooling under solar minimum conditions. The NO radiative power decreased by almost an order of magnitude from 2002 to 2009, whereas the $\mathrm{CO}_{2}$ radiative power decreased only by approximately $35 \%$ according to SABER/TIMED measurements (Mlynczak et al. 2010). Emmert and Picone (2011) dealt with estimating statistical uncertainty of thermospheric density trends. They found that these trends are statistically significant at the 95\% level, and that a sophisticated method of uncertainty estimation must be used because simple classical methods underestimate the uncertainty. Trends in thermospheric density are of high practical importance. Lewis et al. (2011) calculated the increase of space debris concentration due to a decreasing trend in thermospheric density. 

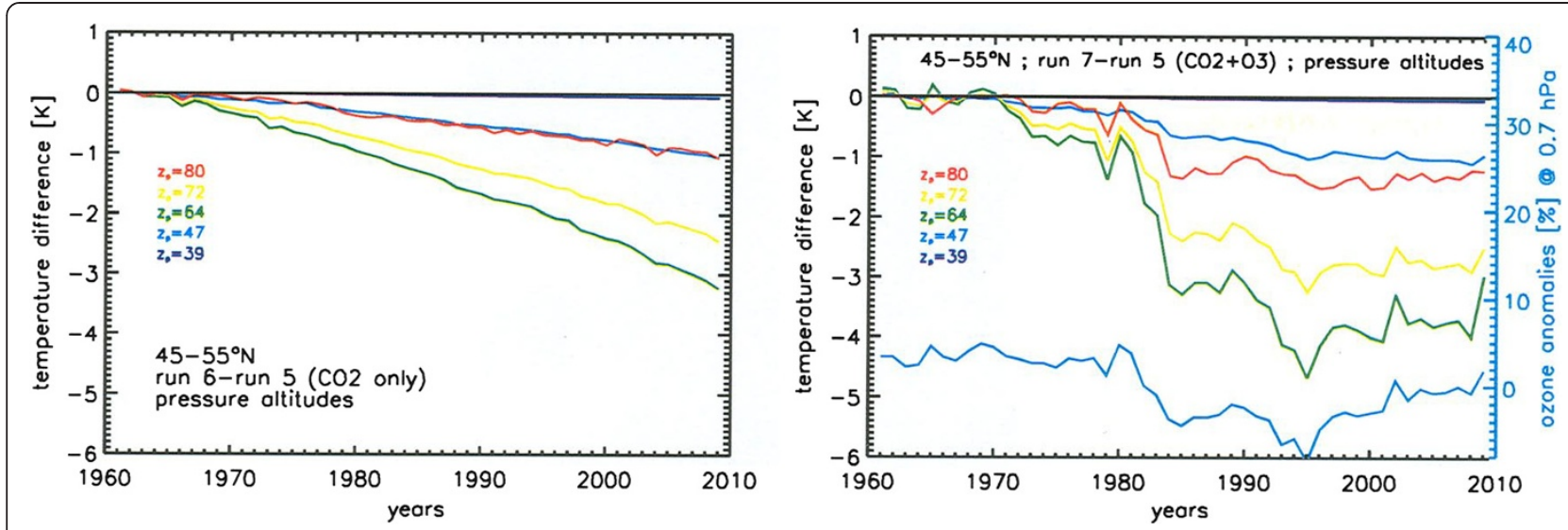

Figure 5 Temperature difference relative to the year 1961. Temperature difference relative to the year 1961 at pressure heights (in kilometers) caused by (left) $\mathrm{CO}_{2}$ trends only and by (right) the combined effect of $\mathrm{CO}_{2}$ and $\mathrm{O}_{3}$. The cyan curve (right) shows the variation of ozone (right axis). After Lübken et al. (2013).

They found a remarkable increase in the concentration of space debris, particularly at low satellite orbits, leading to an increase in the number of damaging collisions of satellites with space debris. According to their calculations, the decline in thermospheric density results in a $74 \%$ increase in the LEO debris population growth rate over a 70 year projection (2009 to 2079).

The last solar activity minimum, particularly years 2008 to 2009, was significantly deeper than any other solar activity minimum during the era of ionospheric and thermospheric investigations, making trend estimations more difficult. Thermospheric densities were extremely low, and the ionosphere behaved partly in an unexpected way. An unexpectedly large decrease of thermospheric density in the recent extreme solar cycle minimum could make a problem in further thermospheric density trend estimates. Therefore, the focus of the CAWSES-II TG-2 project (2) was changed to clarifying the behavior of the ionosphere and thermosphere during this solar minimum. It is necessary to mention that we are not sure how deep the EUV flux decrease was in the last solar minimum. Standard solar indices, sunspot number and F10.7, are unable to describe this decrease. Solomon et al. (2010b) analyzed the extremely low thermospheric neutral densities in the solar minimum year 2008 compared to 1996 and concluded that the observed decrease of the solar EUV flux by $13 \%$ to $15 \%$ (SEM/SOHO observations) can account for this decrease of thermospheric density. Deng et al. (2012) carefully analyzed this density depletion and came to a conclusion that about $75 \%$ was caused by a decrease of the solar EUV irradiance and about $25 \%$ by very quiet geomagnetic activity. This would reduce the 1996 to 2008 EUV difference to some $10 \%$ to $12 \%$. Laštovička (2013b) made an estimate based on noontime (10 to 14 UT) yearly average values of foF2 from very reliable station Juliusruh (the northernmost Germany, geomagnetic latitude $54.3^{\circ} \mathrm{N}$ ). The estimated decrease of the EUV level from 1996 to 2008 is about 7\% to 9\% after considering the effect of changed geomagnetic activity. At the AGU Chapman conference in November 2012, $\mathrm{T}$. Woods (private communication) estimated the difference between the 1996 and 2008 EUV irradiance levels to be probably close to $10 \%$ and within limits of $6 \%$ to $15 \%$ provided by various authors. Emmert et al. (2012), when interpreting the difference between the observed and modeled $\mathrm{CO}_{2}$ concentration in the lower thermosphere, assumed some increase in eddy diffusion to get an agreement between model-based and observed $\mathrm{CO}_{2}$ concentrations. This increase would contribute also to the anomalous thermospheric density decrease in the recent extreme solar minimum (Emmert et al. 2012).

As for ionosphere behavior, Klenzing et al. (2013) found that low latitude ExB drift as measured by C/ NOFS satellite exhibit several differences compared with climatology based on previous solar activity minima including a downward drift in the early afternoon and a weak to non-existing pre-reversal enhancement, which results only can explain the observed post-sunset drop in hmF2. Solomon et al. (2013) fairly well simulated the observed anomalous decrease of electron density and hmF2 in the last solar minimum with model TIE-GCM. The simulation revealed a dominant role of the extreme solar EUV decrease in the last solar minimum together with minor contribution from lower geomagnetic activity and very minor contribution from anthropogenic increase of $\mathrm{CO}_{2}$. Sunda et al. (2013) observed the effects of moderate geomagnetic storms in the equatorial and low latitude ionosphere during the extreme solar minimum to be more severe than under moderate and high solar activity. The same was found for middle latitudes by Buresova et al. (2014). Geomagnetic activity in years 
2008 to 2009 was dominated by sequences of solar wind high speed streams, which resulted in only moderate geomagnetic storms but in a high-intensity, longduration continuous auroral activity (HILDCAA) events. Verkhoglyadova et al. (2013) found surprisingly large enhancements of TEC at low latitudes during such events.

Summarizing, we can say that the ionosphere and thermosphere behaved in a different and partly unexpected way than in the previous solar activity minima. However, quantitatively, the difference is not yet determined enough, its understanding is only partial, and its impact on trend estimating is not sufficiently clear, even though there is some impact.

Zhang and Holt (2013) found the decrease of ion temperature above Millstone Hill to be largest under lower solar activity of $\mathrm{F} 10.7=90$ to 120 but not in the solar activity minimum. This, to some extent, contradicts the behavior of thermospheric density, where the highest decrease was found in the minimum of solar activity.

\section{Are PMC/NLC frequency and brightness trending due to changes in temperature and water vapor?}

The polar mesospheric clouds are observed in the summer polar upper mesosphere (approximately 82 to $85 \mathrm{~km}$ ), i.e., in the region where the lowest atmospheric temperatures are observed. They consist of ice crystals. They are called polar mesospheric clouds (PMC) when observed from above by satellites and noctilucent clouds (NLC) when observed from below the surface. In the investigations of PMC/NLC, there were three open problems. First, PMC and NLC trends were apparently different; second, models did not capture trends in PMC/NLC; and third, it was not clear what the main driver of PMC/NLC trend was, if it water vapor content or temperature. WACCM-PMC model studies show that relatively dim clouds should have different trends than the brighter clouds. Thus comparison of time series of PMC brightness and frequency from different instruments need to consider this 'threshold effect'.

The first problem has been solved by Shettle et al. (2009). They analyzed 28 years of satellite PMC observations for latitudinal bands $50^{\circ} \mathrm{N}$ to $64^{\circ} \mathrm{N}$ (NLC observation latitudes), $64^{\circ} \mathrm{N}$ to $74^{\circ} \mathrm{N}$, and $74^{\circ} \mathrm{N}$ to $82^{\circ} \mathrm{N}$. They observed statistically significant increase only in $74^{\circ} \mathrm{N}$ to $82^{\circ} \mathrm{N}$, whereas in $50^{\circ} \mathrm{N}$ to $64^{\circ} \mathrm{N}$, it was statistically insignificant. At NLC observational latitudes, the PMC trend of Shettle et al. (2009) is $+9.9 \% /$ decade, the NLC trend of Kirkwood et al. (2008) is $+4.4 \% /$ decade for moderate and bright NLCs, and approximately 14\%/decade for all NLCs; all trends being statistically insignificant. This means that the PMC and NLC trends are comparable and do not differ within accuracy of their determination in spite of partly different analyzed periods. Relatively large differences between PMC and NLC results were due to the fact that the occurrence frequency of PMC in the $74^{\circ} \mathrm{N}$ to $82^{\circ} \mathrm{N}$ band is four times as high as in the NLC latitudinal band and, therefore, the $74^{\circ} \mathrm{N}$ to $82^{\circ} \mathrm{N}$ band largely determines the overall trend in PMCs.

The second problem was basically solved recently with model LIMA/ICE. This model captures reasonably well (even quantitatively) the variability of PMC albedo (Lübken et al. 2012), as it is shown in Figure 6. The model simulates reasonably well the long-term behavior of PMCs both as to the solar cycle effect and as to the long-term trends in all three separated latitudinal zones of PMC albedo/brightness and supports the dominant role of high latitudes $\left(74^{\circ} \mathrm{N}\right.$ to $82^{\circ} \mathrm{N}$ ) in both the solar cycle and trend effects in polar mesospheric clouds.

As for the third problem, Rong et al. (2012) analyzed the data of the Solar Occultation for Ice Experiment aboard the Aeronomy of Ice in the Mesosphere satellite (2007 to 2010, 4 years). Their results support the idea that the observational trends in PMC brightness (albedo) are primarily driven by changes in water vapor, not temperature. On the other hand, Remsberg's (2010) HALOE-based results support rather the role of temperature. Model results of Lübken et al. (2012) reveal important role of all three components, temperature, water vapor, and solar Lymna-alpha flux variability in changes of PMC brightness. Recent observations also suggest water vapor from space traffic exhaust may be sufficient to override the expected decrease in PMC as solar activity increases (Siskind et al. 2013). Thus, further research and more data are required to find the dominant driver of PMC trends. Temperature itself $($ T83 km) seems to be the main driver of trend in the height of PMCs, which is, however, very small (Lübken et al. 2012).

LIMA/ICE simulations reveal a change of trend of temperature at the NLC height of $83 \mathrm{~km}$ at high latitudes $\left(69^{\circ} \mathrm{N}\right.$, ALOMAR) in the mid-1990s. The weak

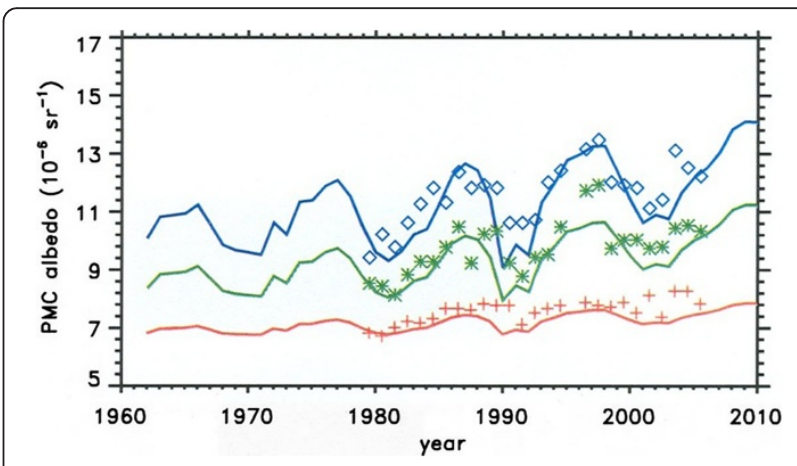

Figure 6 PMC albedos from SBUV measurements and LIMA/ICE model. PMC albedos (brightness) from SBUV measurements (symbols) and LIMA/ICE model (full lines) for $54^{\circ} \mathrm{N}$ to $64^{\circ} \mathrm{N}$ (red), $64^{\circ}$ $\mathrm{N}$ to $74^{\circ} \mathrm{N}$ (green), and $74^{\circ} \mathrm{N}$ to $82^{\circ} \mathrm{N}$ (blue) (Lübken et al. 2012). 
negative trend ( $-2 \mathrm{~K}$ per 35 years) is replaced by a similarly weak but positive trend just when the trends in the northern mid-latitude stratospheric ozone changed from depletion to recovery (Lübken et al. 2012).

A study by Benze et al. (2011) of Solar Backscatter Ultraviolet satellite instrument observations of PMC showed that the onset of the PMC season in the southern hemisphere $(\mathrm{SH})$ is mostly influenced by the timing of the reversal of stratospheric winds in the same hemisphere from the winter to summer state. A secondary influence on SH PMC onset is the solar cycle. Combined, these factors appear to cause over a 40 day swing in the date of PMC onset. These authors, along with Smith et al. (2011) and Lossow et al. (2012), point out that any trend in timing of the reversal of the stratospheric jet could cause a trend in SH PMC onset.

Polar mesospheric summer echoes (PMSE) are phenomenon which correlates with PMCs. Radar observations at Andoya $\left(69.3^{\circ} \mathrm{N}\right)$ over 1994 to 2008 reveal a positive trend in the PMSE occurrence frequency (Latteck and Bremer, 2013), which is qualitatively consistent with PMC trends.

\section{Important results reached outside of the CAWSES-II project TG-2}

The three CAWSES-II TG-2 projects were focused only on some specific important problems of trend investigations and, therefore, some progress was reached also out of the TG-2 activities. This progress is summarized in this section. It should be mentioned that many of these results were reached by CAWSES-II project participants.

One of the problems in the thermosphere and ionosphere is that the model simulations yield weaker trends than the observational data. Emmert et al. (2012) found quite recently that $\mathrm{CO}_{2}$ concentration in the lower thermosphere increases substantially quicker than modelers expected. To repeat model simulations with new values of the $\mathrm{CO}_{2}$ concentration in the lower thermosphere increases is an important challenge for modelers in the near future. It is very desirable to know to which extent these new $\mathrm{CO}_{2}$ concentrations in the lower thermosphere help to reduce the quantitative difference between observed and simulated trends in the thermosphere and ionosphere.

First results about long-term trends in various quantities appeared during the CAWSES-II period but outside of the CAWSES-II projects. At thermospheric and ionospheric heights, the first information appeared on trends in ion and electron temperatures. Figure 7 displays trends of noontime Ti from Millstone Hill over a 100 to $550 \mathrm{~km}$ altitude range (Zhang et al. 2011). Above $200 \mathrm{~km}$, the trends are negative; cooling reaches about $3 \% /$ decade (almost $-4 \mathrm{~K} /$ year). Negative trends were expected because in the thermosphere (100 to $500 \mathrm{~km}), \mathrm{Ti}$ and neutral temperature $(\mathrm{T})$ are relatively closely related (e.g., Akmaev 2012); and both models (e.g., Roble and Dickinson 1989) and neutral density trends (Emmert et al. 2008) suggest thermospheric cooling above 200 $\mathrm{km}$. Trends are apparently positive below $200 \mathrm{~km}$ if they are observed at fixed heights. As a consequence of the thermal contraction of the upper atmosphere together with the steep gradient of temperature in the height range approximately 100 to $200 \mathrm{~km}$, the warm air from above replaces the air at a given height. The effect of local cooling is not sufficient to compensate for the effect of contraction, and therefore, we observe an apparent heating. This effect might be modulated to some extent by associated changes in chemistry and composition (e.g., the $\mathrm{O} / \mathrm{N}_{2}$ ratio). Donaldson et al. (2010) found at Saint Santin negative Ti trends of comparable magnitude above about $150 \mathrm{~km}$ and positive trends below for the period 1966 to 1987. The existence of apparent positive trends in temperature below approximately $150 \mathrm{~km}$ is in qualitative agreement with model simulations (e.g., Qian et al. 2011). The negative trends were increasing with height, and at $350 \mathrm{~km}$, they reached an average of $-3 \mathrm{~K} /$ year. However, they were much larger at noon than at midnight.

Zhang et al. (2011) observed larger trends of Ti for the period 1980 to 2006. Donaldson et al. (2010) found much weaker trends before than after 1979. This breakpoint coincides with the beginning of the period of strongly decreasing stratospheric ozone concentration at northern middle latitudes. This finding together with a large difference between daytime and nighttime trends in Ti prompted Walsh and Oliver (2011) to hypothesize that the ozone depletion may be the main cause of the accelerated cooling after 1979. However, Laštovička (2012) showed that the turnaround of ozone trends at northern middle latitudes (1995 to 1997) is reflected neither in Ti data from Millstone Hill nor in thermospheric density data series. Therefore, trend in $\mathrm{Ti}$ is not affected by ozone; the hypothesis of Walsh and Oliver (2011) was a consequence of too short of a data series at Saint Santin.

Zhang and Holt (2013) analyzed possible dependence of Ti above Millstone Hill on local time, season, solar, and geomagnetic activities. They found strong cooling in daytime but very weak cooling at nighttime. Therefore, the gross average cooling in 200 to $350 \mathrm{~km}$ (where $\mathrm{Ti} \sim \mathrm{Tn}$ ) is $-4 \mathrm{~K} /$ decade, a trend close to estimates of $\mathrm{Tn}$ trends derived from thermospheric density trends. No consistent and substantial seasonal variation of cooling was found. A slight increase of cooling with increasing geomagnetic activity was observed.

Qian et al. (2011) simulated changes in Ti in response to doubling $\mathrm{CO}_{2}$ during solar minimum conditions. Up to about an altitude of $350 \mathrm{~km}$, the results of simulations 

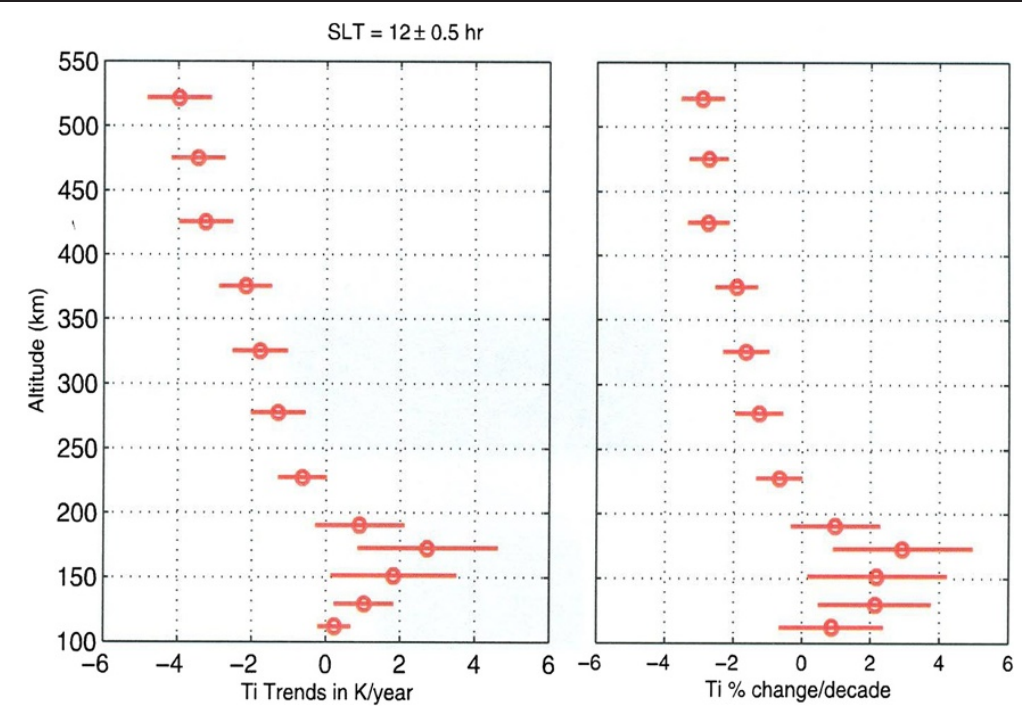

Figure 7 Trends in ion temperature as measured by the incoherent scatter radar. Trends in ion temperature as measured by the incoherent scatter radar at Millstone Hill, noontime, 1968 to 2006, heights 100 to 550 km (Zhang et al. 2011).

qualitatively agree with observations from Millstone Hill and Saint Santin, but above $350 \mathrm{~km}$ simulations provide a result opposite to the above observations, i.e., strong heating. The heating might be caused by atmospheric contraction in combination with Ti increasing with altitude in the uppermost thermosphere, a similar effect like that in 100 to $120 \mathrm{~km}$ altitudes. However, Akmaev (2012) claims that at a higher solar activity, the region of positive change in Ti might be shifted to much higher altitudes and, thus, not seen in radar data. This might result in the absence of the upper region of positive trends in Ti in the average trends presented in Figure 7.

High-latitude results by Ogawa et al. (2012) based on Ti data from EISCAT at Tromso differ from those of mid-latitude stations Millstone Hill and Saint Santin. A 30 year long (1981 to 2011) data series from Tromso yields for 11 to $12 \mathrm{LT}$ a negative trend below $400 \mathrm{~km}$, which is twice as strong as the trend simulated by Qian et al. (2011) but only of a half magnitude of Millstone Hill and Saint Santin trends. Upward, the trend quickly weakens and above $450 \mathrm{~km}$ it becomes positive. The trend in Ti somewhat depends on the solar proxy used (F10.7, F10.7aver, Mg II), but the differences are not large. There is also some dependence of trends at heights of about 400 to $450 \mathrm{~km}$ on local time. The trend in $\mathrm{Ti}$ is more negative near noon (11 to $14 \mathrm{LT}$ ) and more positive in the morning ( 08 to $11 \mathrm{LT}$ ).

The mid-latitude stations Millstone Hill and Saint Santin show at high altitudes negative trends, whereas the high latitude station Tromso and model simulations by Qian et al. (2011) show positive trends. Thus, there is an evident discrepancy, which needs to be analyzed and its origin looked for. Moreover, the absolute value of trends in Ti reported for mid-latitude stations Millstone Hill and Saint Santin is by about an order of magnitude higher than expected from model simulations of trends in neutral temperature (Qian and Solomon 2012) and trends in thermospheric densities derived from satellite drag (Emmert et al. 2008), as noticed by Akmaev (2012). The origin of this discrepancy is not yet known.

Oliver et al. (2013) claim that thermospheric cooling derived from ion temperature measurements above Millstone Hill is remarkably larger than the cooling necessary to explain the observed decrease of thermospheric density (however this is not confirmed by Zhang and Holt 2013). They try to explain this discrepancy by the effect of long-term changes in the gravity wave flux in the thermosphere initiated by a shift in climate regime in oceans in 1976/77, which launched a slow Rossby wave across oceans that continues to propagate until present. However, this hypothesis needs to be confirmed by observations and further model simulations.

As concerns the electron temperature Te, the first result on trends appeared based on Millstone Hill data (Zhang et al. 2011). It reveals positive trends in Te even though they are relatively little significant due to large scatter of data. At high altitudes, the positive trends may be due to the negative trends in electron density. The Te trend qualitatively agrees with model simulations by Qian et al. (2011). However, more data are needed to get statistically reliable trends as well as information from other measuring sites.

Available neutral temperature (Tn) data do not allow calculation of trends but based on trends in ion temperature and thermospheric neutral density we may expect trends qualitatively similar to those in $\mathrm{Ti}$. 
First results also appeared in long-term trends in the thermospheric neutral winds based on data series derived from Fabry-Perot nightglow measurements over Arecibo, 1980 to 2010 (Brum et al. 2012). These measurements are from heights near or slightly below the F2 region maximum. The trends reveal a complex pattern; they are strongly dependent (even as to sign) on the day of year and the time of night. However, if we take into account the behavior of long-term changes and trends in mesospheric and mesopause region winds as observed and also modeled (Qian et al. 2011), the existence of a complex pattern of trends in thermospheric wind is not surprising. Information on trends in thermospheric winds is required also from other sites, particularly if we take into account the behavior of MLT region wind trends, which are locally different.

The first information on trends also appeared for the total electron content (TEC) based on the International Geodetic Service (IGS) TEC maps over 1995 to 2010

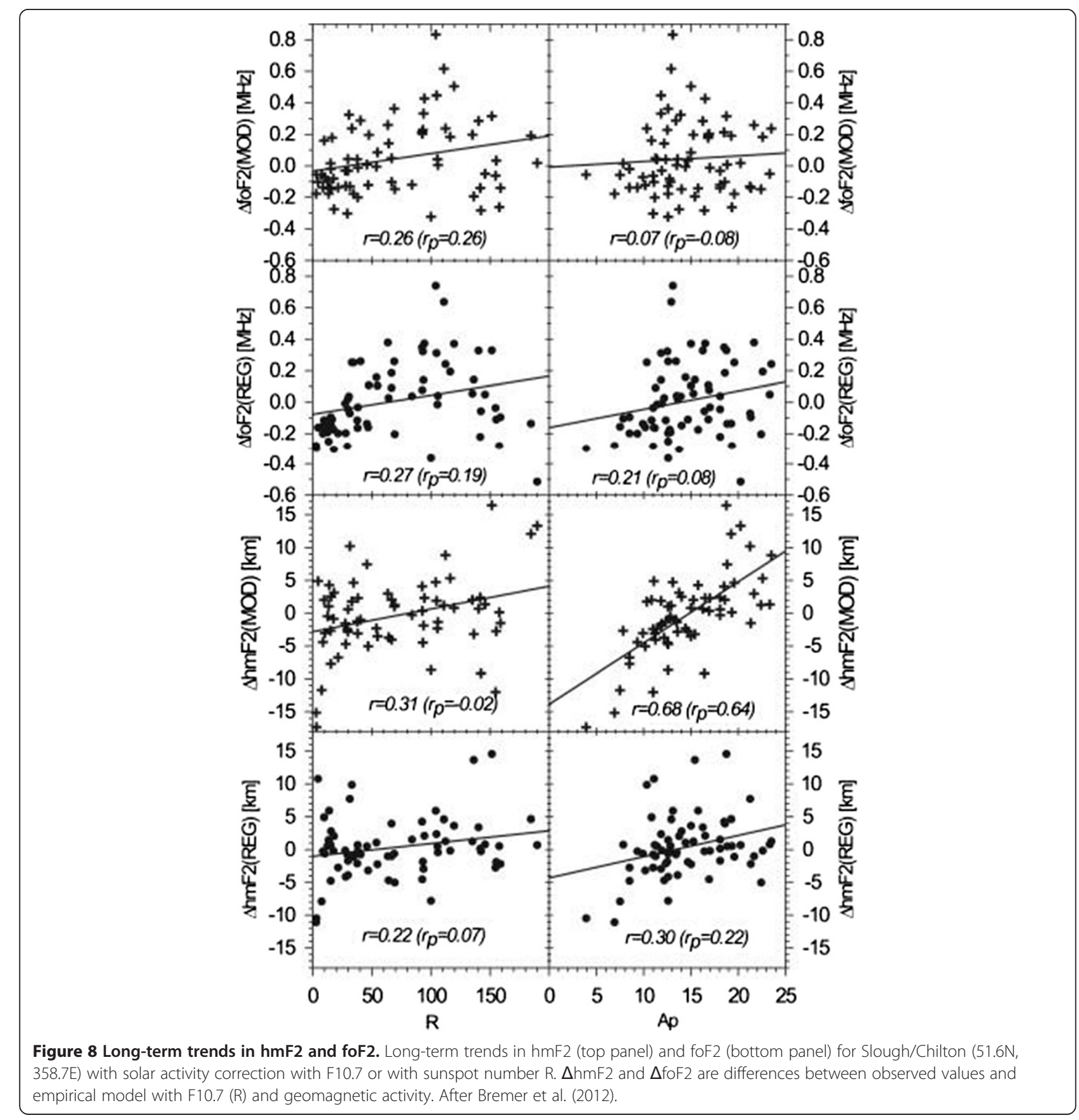


(Lean et al. 2011). These trends were strongly regionally dependent and predominantly positive. In some regions, like Europe, they are surprisingly strong and positive. Laštovička (2013b) showed that ionospheric trends in the period 1995 to 2010 were in general more positive than before, perhaps due to the extreme solar minimum 2008 to 2009, but TEC trends were more positive than foF2 trends in the past as well. Longer data series is necessary to clarify the potential impact of the last solar minimum on trends in TEC.

Danilov (2009) and Danilov and Vanina-Dart (2010) used behavior of ionospheric parameters foF2 and hmF2 including their scatter to deduce changes of trends in thermospheric dynamics. They found no trend before about 1980 but a systematic long-term trend after about 1980. They attributed this trend to the greenhouse cooling of the middle and upper atmosphere.

Bremer et al. (2012) and Mielich and Bremer (2013) used a new worldwide homogenized database of foF2 and $\mathrm{M}(3000) \mathrm{F} 2$ to calculate long-term trends in foF2 and hmF2. They conclude that the global trends in yearly values of foF2 are very small and do not differ significantly from no trend. This is supported by model calculations of the greenhouse gas effects on foF2 because hmF2 closely follows the boundary between the increasing electron density below and decreasing electron density above, only a small trend in foF2 is expected (e.g., Qian et al. 2009). On the other hand, global trends in hmF2 are negative and statistically significant, again in qualitative agreement with model calculations of the greenhouse gas effect on hmF2. Bremer et al. (2012) and Mielich and Bremer (2013) also confirm and demonstrate for global data the necessity to use F10.7, not sunspot number for correction to solar activity (solar cycle), as it is illustrated by Figure 8. Mielich and Bremer (2013) shows that for F2 region trends F10.7 is even better than E10.7 index (Tobiska's ionospheric data-based index for description of solar EUV flux, which is close to F10.7) due to problems of the latter in 1957 to 1958. Trends based on the correction with F10.7 are larger and with the same or smaller uncertainty and stronger correlation than those based on the correction with sunspot numbers. The way how the correction for solar activity is made appears at least as important as the method how the trend is calculated, particularly for foF2. It is also necessary to mention that we cannot expect quite homogeneous trends globally, because in some areas, particularly in the low-latitude South America, secular changes in the Earth's magnetic field plays an important role (e.g., Cnossen and Richmond, 2008), and at high latitudes, the influence of long-term changes in geomagnetic activity has to play more important role than at middle and low latitudes. Historical values of trends in fofF2 and hmF2 as published by various author were different and sometimes even of opposite sign. A part of these differences was caused by using sunspot number versus F10.7 and in some cases also by data quality problems. However, recent results indicate also other reasons. Model calculations by Qian et al. (2009) show that on a global average basis, trends of foF2 are larger under solar minimum conditions and the global distribution of the trends tends to be more structured. The trends of foF2 are larger in the winter hemisphere than in the summer hemisphere, for both solar minimum and maximum conditions. Danilov (2012) claims that a strong influence of dynamical processes on foF2 at night compared to a weak influence during daytime may result in some difference between daytime and nighttime trends in foF 2 and hmF2. As for trends of hmF2, they exhibit strong latitudinal, longitudinal, and diurnal variations; they are mostly negative but can be positive at night in some regions according to model calculations by Qian et al. (2009). Bremer et al. (2012) found stronger trends at lower than higher latitudes both in foF2 and hmF2, but the latitudinal dependence of trends was rather weak. All that can contribute to partly different results of various authors about trends in the F2 region.

Danilov and Konstantinova (2012) studied trends in foF2 over 1990 to 2010 based on data of 22 ionospheric stations. They found that trends in 1998 to 2010 were more negative than in 1990 to 1997. They interpret this finding as more important role of temperature (i.e., of greenhouse cooling) in the latter period. However, Laštovička (2013b) (found more positive trends in the period 1995 to 2010 than before, which contradicts the results of Danilov and Konstantinova (2012). Danilov and Konstantinova (2013) compared trends of foF2 based on different databases and found some, even though not principal, differences between them. They also reported twice as high negative trends in foF2 in winter compared to summer and remarkably larger standard deviations from the dependence of foF2 on F10.7 in 1998 to 2010 compared to 1958 to 1979; the latter maybe due to a larger variability of thermospheric winds. Scott et al. (2014) reported long-term changes in amplitude ratio of semiannual/ annual variations of foF 2 for Slough/Chilton $\left(52^{\circ} \mathrm{N}\right)$ and Stanley $\left(52^{\circ} \mathrm{S}\right)$. They attributed these changes to long-term changes in geomagnetic activity induced changes in thermospheric circulation and composition.

Another quantity which displays a long-term trend is the solar quiet $(\mathrm{Sq})$ geomagnetic variation but this trend qualitatively agrees with the secular variation of the Earth magnetic field strength, so it is not of greenhouse gas origin (de Haro Barbas et al. 2013). 


\section{Conclusions}

The TG-2 of CAWSES-II covered several important problems in the investigation of long-term trends in the upper atmosphere and ionosphere, but not the full spectrum of problems. Nevertheless, its contribution to the overall progress in the field of long-term trend was substantial. Some of these results are as follows:

1. The scenario of trends in the upper atmosphere and ionosphere became more complete and some discrepancies were removed or explained.

2. The role of stratospheric ozone and recovery or leveling off of its trend in the mid-1990s to later-1990s was proved to be remarkable and its impact on trends in the mesosphere, lower thermosphere and lower ionosphere was to a significant extent quantified.

3. A reasonable agreement between observations and simulations of trends in mesospheric temperatures and PMC albedo has been reached.

4. Generally, the progress in the field of PMC/NLC trends was substantial and several problems were solved.

5. Some progress in several other problems has also been reached including understanding of why the thermospheric density trends are much stronger under solar cycle minimum conditions, and of behavior of the upper atmosphere-ionosphere system in the extreme solar minimum 2008 to 2009 with impact on trends and their estimating.

Moreover, CAWSES-II TG-2 scientists made progress in the study trend topics outside the TG-2 itself.

Main tasks for future research on long-term trends are as follows:

1. The key open problem is trends in atmospheric dynamics, i.e., in atmospheric circulation and particularly in atmospheric wave activity. Atmospheric waves affect many parameters of the upper atmosphere and ionosphere. Relatively little progress was reached. However, now we are sure that trends in circulation are of a complex spatial pattern.

2. The agreement between observations and models is still only qualitative for many parameters. Reducing the quantitative discrepancy between observed and simulated trends is of high importance. It will result also in better understanding of mechanisms responsible for trends.

3. Trends are known mostly qualitatively, not quantitatively. Specifying and quantifying trends in various parameters and studying various finer details of trend behavior are tasks for future research. Some apparent discrepancies like those in ion temperature trends need to be explained.
4. The changing role of trend drivers induces spatial and particularly temporal changes of trends in various parameters. This has to be monitored and further studied.

5. On longer time scales, an important task is to try to join the upper atmospheric trends with long-term changes in the stratosphere into one scenario (if it is physically possible). As a first step, similarities and differences between upper atmospheric and stratospheric trends began to be studied.

Progress in studying the long-term trends in the mesosphere, thermosphere, and ionosphere over the period of CAWSES-II project are significant but still various questions remain open. Therefore in the CAWSES-II follow-up new SCOSTEP program VarSITI, project ROSMIC (Role Of the Sun and the Middle atmosphere/thermosphere/ ionosphere In Climate), two of four working groups deal with long-term trends: WG-3 Trends in mesosphere and lower thermosphere, and WG-4 Trends and solar cycle effects in the thermosphere.

\section{Abbreviations}

AE: index of auroral zone geomagnetic activity; AGU: American Geophysical Union; ALOMAR: Arctic Lidar Observatory for Middle Atmospheric Research; CAWSES-II: Climate and Weather of the Sun-Earth System; C/ NOFS: Communications/Navigation Outage Forecasting System satellite; EISCAT: European Incoherent Scatter Scientific Association; EUV: extreme ultraviolet radiation; GCM: global circulation model; GHG: greenhouse gases; GPS: Global Positioning System; HALOE: Halogen Occultation Experiment satellite; HILDCAA: high-intensity long-duration continuous AE activity; HRDI: high-resolution Doppler imager; IAGA: International Association of Geomagnetism and Aeronomy; ICMA: International Commission for the Middle Atmosphere; IPCC: Intergovernmental Panel on Climate Change; LASP: Laboratory for Atmospheric and Space Physics; LEO: low Earth orbiting; LIMA: Leibniz Institute Middle Atmosphere model; LIMA/ICE: Leibniz Institute Middle Atmosphere/lce model; MLT: mesosphere-lower thermosphere; MLTI: mesosphere-lower thermosphere-ionosphere; NCAR: National Center for Atmospheric Research; NH: Northern Hemisphere; NLC: Noctilucent clouds; OHP: Observatory of Haute Provence; PMC: polar mesospheric clouds; ROSMIC: role of the sun and the middle atmosphere/thermosphere/ ionosphere in climate; SABER: Sounding of the Atmosphere using Broadband Emission Radiometry instrument; SCOSTEP: Scientific Committee for SolarTerrestrial Physics; SEM: solar EUV monitor instrument; SH: Southern Hemisphere; SOHO: Solar and Heliospheric Observatory; TEC: total electron content; TG: topical group; TIE: Thermosphere-Ionosphere-Electrodynamics model; Te: electron temperature; Ti: ion temperature; Tn: neutral temperature; TIMED: Thermosphere Ionosphere Mesosphere Energetics and Dynamics satellite; UARS: Upper Atmospheric Research Satellite;

UCEMA: University Center of Macroeconomic Studies of Argentina; UT: Universal Time; VarSITI: Variability of the Sun and Its Terrestrial Impact; VLF: very low frequency; WACCM: Whole Atmospheric Community Climate Model.

\section{Competing interests}

The authors declare that they have no competing interests.

\section{Authors' contributions}

The three authors altogether chaired the CAWSES-II TG-2. JL wrote most of the paper. DM wrote the 'Are there long-term changes in tropospheric wave generation and their propagation through a changing atmosphere?' section, modified several other sections, particularly the 'By how much is the anthropogenic effect on the ionosphere/thermosphere enhanced during a quiet sun period?' section, and corrected the English grammar language of the paper. GB contributed substantially to the 'Are trends related to upward 
propagation of atmospheric waves observed in the mesosphere, lower thermosphere and ionosphere (MLTI)?' section. All authors read and approved the final manuscript.

\section{Acknowledgements}

The authors are grateful to many collaborators of CAWSES-II TG-2, particularly to the project leaders for their efforts. JL acknowledges the support by the Grant Agency of the Czech Republic, grant P209/10/1792, and the Ministry of Education, Youth and Sports of the Czech Republic, grant LD 12070. The National Center for Atmospheric Research is operated by the University Corporation for Atmospheric Research under the sponsorship of the National Science Foundation.

\section{Author details}

'Institute of Atmospheric Physics ASCR, Bocni II, Prague 14131, Czech Republic. ${ }^{2}$ Indian Institute for Tropical Meteorology, Dr. Homi Bhabha Road, Pashan, Pune 411008, India. ${ }^{3}$ National Center for Atmospheric Research, Boulder 80301CO, USA.

\section{Received: 16 May 2014 Accepted: 16 September 2014}

\section{Published online: 11 November 2014}

\section{References}

Akmaev RA (2012) On estimation and attribution of long-term temperature trends in the thermosphere. J Geophys Res 117:A09321, doi: 10.1029/ 2012JA018058

Angot G, Keckhut P, Hauchecorne A, Claud C (2012) Contribution of stratospheric warmings to temperature trends in the middle atmosphere from the lidar series obtained at Haute-Provence Observatory (44N). J Geophys Res 117: D21102, doi: 10.1029/2012JD017631

Batista PP, Clemesha BR, Simonich DM (2009) A 14-year monthly climatology and trend in the $35-65 \mathrm{~km}$ altitude range from Rayleigh Lidar temperature measurements at a low latitude station. J Atmos Solar-Terr Phys 71:1456-1462, doi: 10.1016/j.jastp.2008.03.005

Beig G (2011) Long-term trends in the temperature of the mesosphere/lowe thermosphere region: 1. Anthropogenic influences. J Geophys Res 116: A00H11, doi: 10.1029/2011JA016646

Beig G, Keckhut P, Lowe RP, Roble RG, Mlynczak MG, Scheer J, Fomichev VI, Offermann D, French WJR, Shepherd MG, Semenov Al, Remsberg EE, She C-Y, Lübken F-J, Bremer J, Clemesha BR, Stegman J, Sigernes F, Fadnavis S (2003) Review of mesospheric temperature trends. Rev Geophys 41(4):1015, doi:10.1029/2002RG000121

Benze S, Randall CE, DeLand MT, Thomas GE, Bailey SM, Russell JM III, Merkel AW (2011) Evaluation of AIM CIPS measurements of polar mesospheric clouds by comparison with SBUV data. J Atmos Solar-Terr Phys 73:2065-2072, doi: 10.1016/j.jastp.2011.02.00

Bougher SW, Roble RG (1991) Comparative terrestrial planet thermospheres. 1. Solar cycle variations of global mean temperatures. J Geophys Res 96:11045-11055

Bremer J, Laštovička J, Mikhailov AV, Altadill D, Bencze P, Buresova D, De Franceschi G, Jacobi C, Kouris S, Perrone L, Turunen E (2009) Climate of the upper atmosphere. Annals Geophys 52:273-299

Bremer J, Damboldt T, Mielich J, Suessmann P (2012) Comparing long-term trends in the ionospheric F2-region with two different methods. J Atmos Solar-Terr Phys 77:174-185, doi: 10.1016/j.jastp.2011.12.017

Brum CGM, Tepley CA, Fentzke JT, Robles E, Terra dos Santos P, Gonzalez SA (2012) Long-term changes in the thermospheric neutral winds over Arecibo: climatology based on over three decades of Fabry-Perrot observations. J Geophys Res 117:A00H14, doi: 10.1029/2011JA016458

Buresova D, Laštovička J, Hejda P, Bochnicek J (2014) lonospheric disturbances under low solar activity conditions. Adv Space Res http://dx.doi.org/10.1016/j. asr.2014.04.007

Cicerone RJ (1990) Greenhouse cooling up high. Nature 344:104-105

Clilverd MA, Clark TGC, Clarke E, Rishbeth H (1998) Increased magnetic storm activity from 1868 to 1995. J Atmos Solar-Terr Phys 60:1047-1056

Cnossen I, Richmond AD (2008) Modeling the effect of changes in the Earth's magnetic field from 1957 to 1997 on the ionospheric hmF2 and foF2 parameters. J Atmos Solar-Terr Phys 70:1512-1524

Cnossen I, Richmond AD (2013) Changes in the Earth's magnetic field over the past century: effects on the ionosphere-thermosphere system and solar quiet (Sq) magnetic variation. J Geophys Res 118:849-858
Danilov AD (2009) Scatter of hmF2 values as an indicator of trends in thermospheric dynamics. J Atmos Solar-Terr Phys 71:1586-1591, doi: 10.1016/ j.jastp.2009.03.002

Danilov AD (2012) Long-term trends in the upper atmosphere and ionosphere (a review). Geomagn Aeron 52:271-291

Danilov AD, Konstantinova AV (2012) Variations in foF2 at the end of the 1990s and the beginning of the 2000s according to the SPIDR system data. Geomagn Aeron 52:350-355

Danilov AD, Konstantinova AV (2013) Trends in the F2 layer parameters at the end of the 1990s and the beginning of the 2000s. J Geophys Res Atmos 118:5947-5964, doi: 10.1002/jgrd.50501

Danilov AD, Vanina-Dart LB (2010) Parameters of the ionospheric F2 layer as a source of information on trends in thermospheric dynamics. Geomagn Aeron 50:187-200

de Haro Barbas BF, Elias AG, Cnossen I, Zossi de Artigas M (2013) Long-term changes in solar quiet (Sq) geomagnetic variations related to Earth's magnetic field secular variation. J Geophys Res 118:3712-3718, doi: 10.1002/ jgra.50352

Deng Y, Huang Y, Solomon S, Qian L, Knipp D, Weimer DR, Wang J-S (2012) Anomalously low geomagnetic energy inputs during 2008 solar minimum. J Geophys Res 117:A09307, doi: 10.1029/2012JA018039

Donaldson JK, Wellman TJ, Oliver WL (2010) Long-term change in thermospheric temperature above Saint Santin. J Geophys Res 115:A11305, doi: 10.1029/ 2010JA015346

Dyrland ME, Sigernes F (2007) An update on the hydroxyl airglow temperature record from the Auroral Station in Adventdalen, Svalbard (1980-2005). Can J Phys 85:143-151

Emmert JT, Picone JM (2011) Statistical uncertainty of 1967-2005 thermospheric density trends derived from orbital drag. J Geophys Res 116:A00H09, doi:10.1029/2010JA016382

Emmert JT, Picone JM, Meier RR (2008) Thermospheric global average density trends, 1967-2007, derived from orbits of 5000 near-Earth objects. Geophys Res Lett 35:L05101, doi: 10.1029/2007GL032809

Emmert JT, Stevens MH, Bernath PF, Drob DP, Boone CD (2012) Observations of increasing carbon dioxide concentration in Earth's thermosphere. Nat Geosci 5:868-871, doi: 10.1038/NGEO1626

Engel A, Möbius T, Bönisch H, Schmidt U, Heinz R, Levin I, Atlas E, Aoki S, Nakazawa T, Sugawara S, Moore F, Hurst D, Elkins J, Schauffler S, Andrews A, Boering K (2009) Age of stratospheric air unchanged within uncertainties over the past 30 years. Nat Geosci 2:28-31, doi: 10.1038/ ngeo388

Ern M, Preusse P, Gille JC, Hepplewhite CL, Mlynczak MG, Russell JM III, Riese M (2011) Implications for atmospheric dynamics derived from global observations of gravity wave momentum flux in stratosphere and mesosphere. J Geophys Res 116:D19107, doi: 10.1029/2011JD015821

Ern M, Arras C, Faber A, Froehlich K, Jacobi C, Kalisch S, Krebsbach M, Preusse P, Schmidt T, Wickert J (2013) Observations and ray tracing of gravity waves: implications for global modeling. In: Luebken F-J (ed) Climate and weather of the Sun-earth system (CAWSES): highlights from a priority program, 383-408. Springer, Dordrecht, The Netherlands, doi: 10.1007/978-94-007-4348-9_21

Eyring V, Cionni I, Bodeker GE, Charlton-Perez AJ, Kinnison DE, Scinocca JF, Waugh DW, Akiyoshi H, Bekki S, Chipperfield MP, Dameris M, Dhomse S, Frith SM, Garny H, Gettelman A, Kubin A, Langematz U, Mancini E, Marchand M, Nakamura T, Oman LD, Pawson S, Pitari G, Plummer DA, Rozanov E, Shepherd TG, Shibata K, Tian W, Braesicke P, Hardiman SC, et al (2010) Multi-model assessment of stratospheric ozone return dates and ozone recovery in CCMVal-2 models. Atmos Chem Phys 10:9451-9472, doi: 10.5194/acp-10-9451-2010

Graigmile PF, Guttorp P, Percival DB (2004) Trend assessment in a long memory dependence model using the discrete wavelet transform. Environmetrics 15:313-315

Hall CM, Dyrland ME, Tsutsumi M, Mulligan FJ (2012) Temperature trends at 90 $\mathrm{km}$ over Svalbard, Norway, $\left(78^{\circ} \mathrm{N}, 16^{\circ} \mathrm{E}\right)$, seen in one decade of meteor radar observations. J Geophys Res 117:D08104, doi: 10.1029/2011JD017028

Hardiman SC, Butchart N, Calvo N (2013) The morphology of the Brewer-Dobson circulation and its response to climate change in CMIP5 simulations. Q J Roy Meteorol Soc doi: 10.1002/qj.2258

Harris NRP, Kyrö E, Staehelin J, Brunner D, Andersen SB, Godin-Beekmann S, Dhomse S, Hadjinicolaou P, Hansen G, Isaksen I, Jrrar A, Karpetchko A, Kivi R, Knudsen B, Krizan P, Lastovicka J, Maeder J, Orsolini Y, Pyle JA, Rex M, Vanicek K, Weber M, Wohltmann I, Zanis P, Zerefos C (2008) Ozone trends at northern mid and high latitudes - a European perspective. Ann Geophys 26:1207-1220 
Hoffmann P, Rapp M, Singer W, Keuer D (2011) Trends in mesospheric gravity waves at northern middle latitudes during summer. J Geophys Res 116: D00P08, doi: 10.1029/2011JD015717

IPCC (2013) Summary for Policymakers. In: Stocker TF, Qin D, Plattner G-K, Tignor M, Allen SK, Boschung J, Nauels A, Xia Y, Bex V, Midgley PM (eds) Climate Change 2013: The Physical Science Basis. Contribution of Working Group I to the Fifth Assessment Report of the Intergovernmental Panel on Climate Change, Cambridge University Press, Cambridge, United Kingdom and New York, NY, USA

Jacobi C, Beig G (2013) Changes in MLT dynamics and composition. Invited paper presented at International CAWSES-II Symposium, Nagoya

Jacobi C, Hoffmann P, Liu RQ, Križan P, Laštovička J, Merzlyakov EG, Solovjova TV, Portnyagin YI (2009) Midlatitude mesopause region winds and wave sand comparison with stratospheric variability. J Atmos Solar-Terr Phys 71:1540-1546

Jacobi C, Hoffmann P, Liu RQ, Merzlyakov EG, Portnyagin YI, Manson AH, Meek CE (2012) Long-term trends, their changes, and interannual variability of Northern Hemisphere midlatitude MLT winds. J Atmos Solar-Terr Phys 75:81-91, doi: 10.1016/j.jastp.2011.03.016

Keckhut P, Schmidlin FJ, Hauchecorne A, Chanin ML (1999) Stratospheric and mesospheric cooling trend estimates from U.S. rocketsondes at low latitude stations $\left(8^{\circ} \mathrm{S}-34^{\circ} \mathrm{N}\right)$, taking into account instrumental changes and natural variability. J Atmos Solar-Terr Phys 61:447-459, doi: 10.1016/S1364-6826(98) 00139-4

Kirkwood S, Dalin P, Réchou A (2008) Noctilucent clouds observed from the UK and Denmark - trends and variations over 43 years. Ann Geophys 26:1243-1254

Klenzing J, Burrell AG, Heelis RA, Huba JD, Pfaff R, Simoes F (2013) Exploring the role of ionospheric drivers during the extreme solar minimum of 2008. Ann Geophys 31:2147-2156, www.ann-geophys.net/31/2147/2013/

Laštovička J (2005) On the role of solar and geomagnetic activity in long-term trends in the atmosphere-ionosphere system. J Atmos Solar-Terr Phys 67:83-92

Laštovička J (2012) On the role of ozone in the long-term trends in the upper atmosphere-ionosphere system. Ann Geophys 30:811-816, doi: 10.5194/ angeo-30-811-2012

Laštovička J (2013a) Trends in the upper atmosphere and ionosphere: recent progress. J Geophys Res 118:3924-3935, doi: 10.1002/jgra.50341

Laštovička J (2013b) Are trends in total electron content (TEC) really positive? J Geophys Res 118:3831-3835, doi: 10.1002/jgra.50261

Laštovička J, Akmaev RA, Beig G, Bremer J, Emmert JT (2006a) Global change in the upper atmosphere. Science 314:1253-1254

Laštovička J, Mikhailov AV, Ulich T, Bremer J, Elias AG, Ortiz de Adler N, Jara V, Abarca del Rio R, Foppiano AJ, Ovalle E, Danilov AD (2006b) Long-term trends in foF2: a comparison of various methods. J Atmos Solar-Terr Phys 68:1854-1870

Laštovička J, Akmaev RA, Beig G, Bremer J, Emmert JT, Jacobi C, Jarvis MJ, Nedoluha G, Portnyagin YI, Ulich T (2008a) Emerging pattern of global change in the upper atmosphere and ionosphere. Ann Geophys 26:1255-1268

Laštovička J, Yue X, Wan W (2008b) Long-term trends in foF2: their estimating and origin. Ann Geophys 26:593-598

Laštovička J, Križan P, M. Kozubek M (2010) Long-term trends in the middle atmosphere dynamics at northern middle latitudes - one regime or two different regimes? Atmos Chem Phys Discuss 10:2631-2668, www.atmoschem-phys-discuss.net/10/2633/2010/

Laštovička J, Solomon SC, Qian L (2012) Trends in the neutral and ionized upper atmosphere. Space Sci Rev 168:113-145, doi: 10.1007/s11214-011-9799-3

Latteck R, Bremer J (2013) Long-term changes of polar mesospheric summer echoes at $69^{\circ} \mathrm{N}$. J Geophys Res Atmos 118:10441-10448, doi: 10.1002/ jgrd.50787

Lean J, Emmert JT, Picone JM, Meier RR (2011) Global and regional trends in ionospheric electron content. J Geophys Res 116:A00H04, doi: 10.1029/ 2010JA016378

Lewis HG, Saunders A, Swinerd G, Newland RJ (2011) Effect of thermospheric contraction on remediation of the near-Earth space debris environment. J Geophys Res 116:A00H08, doi: 10.1029/2011JA016482

Lossow S, McLandress C, Jonsson Al, Shepherd TG (2012) Influence of the Antarctic ozone hole on the polar mesopause region as simulated by the Canadian Middle Atmosphere Model. J Atmos Solar-Terr Phys 74:111-123, doi: 10.1016/j.jastp.2011.10.010
Lübken F-J, Berger U, Kiliani J, Baumgarten G, Fiedler J (2012) Solar variability and trend effects in mesospheric ice layers. In: Lübken F-J (ed) Climate And Weather of the Sun-Earth System (CAWSES), 18th edn. Springer, Dordrecht, Netherlands, pp 317-338, doi:10.1007/978-94-007-4348-9

Lübken F-J, Berger U, Baumgarten U (2013) Temperature trends in the midlatitude summer mesosphere. J Geophys Res Atmos 118:13347-13360, doi:1002/ 2013JD020576

Martini D, Mursula K (2008) Centennial geomagnetic activity studied by a new, reliable long-term index. J Atmos Solar-Terr Phys 70:1074-1087

Mielich J, Bremer J (2013) Long term trends in the ionospheric F2 region with different solar activity indices. Ann Geophys 21:291-303

Mlynczak M, Hunt L, Marshall BT, Martin-Torres FJ, Mertens CJ, Russell JM III, Remsberg E, Lopez-Puertas M, Picard R, Winick J, Wintersteiner P, Thompson RE, Gordley LL (2010) Observations of infrared radiative cooling in the thermosphere on daily to multiyear timescales from the TIMED/SABER instrument. J Geophys Res 115:A03309, doi: 10.1029/2009JA014713

Offermann D, Hoffmann P, Knieling P, Koppmann R, Oberheide J, Steinbrecht W (2010) Long-term trends and solar cycle variations of mesospheric temperature and dynamics. J Geophys Res 115:D18127, doi: 10.1029/ 2009JD013363

Ohya H, Shiokawa K, Miyoshi Y (2011) Long-term variations in tweek reflection height in the D and lower E regions of the ionosphere. J Geophys Res 116: A10322, doi: 10.1029/2011JA016800

Oliver WL, Zhang S-R, Goncharenko LP (2013) Is thermospheric global cooling caused by gravity waves? J Geophys Res 118:3898-3908, doi: 10.1002/ jgra. 50370

Qian L, Solomon SC (2012) Thermospheric density: an overview of temporal and spatial variations. Space Sci Rev 168:147-173, doi: 10.1007/s11214-011-9810-z

Qian L, Burns AG, Solomon SC, Roble RG (2009) The effect of carbon dioxide cooling on trends in the F2-layer ionosphere. J Atmos Solar-Terr Phys 71:1592-1601, doi: 10.1016/j.jastp.2009.03.006

Qian L, Laštovička J, Solomon SC, Roble RG (2011) Progress in observations and simulations of global change in the upper atmosphere. J Geophys Res 116 : A00H03, doi: 10.1029/2010JA016317

Qian L, Marsh D, Merkel A, Solomon SC, Roble RG (2013) Effects of trends of middle atmosphere gases on the mesosphere and thermosphere. J Geophys Res Space Phys 118:3846-3855, doi:10.102/jgra.50354

Rao NV, Tsuda T, Riggin DM, Gurubaran S, Reid IM, Vincent RA (2012) Long-term variability of mean winds in the mesosphere and lower thermosphere at low latitudes. J Geophys Res 117:A10312, doi: 10.1029/2012JA017850

Ratnam MV, Kumar GK, Murthy BVK, Patra AK, Rao WMJ, Rao SVB, Kumar KK, Ramkumar G (2008) Long-term variability of the low latitude mesospheric $\mathrm{SAO}$ and $\mathrm{QBO}$ and their relation with stratospheric QBO. Geophys Res Lett 35:L21809, doi: 10.1029/2008GL035390

Ratnam MV, Kumar GK, Rao NV, Krishna Murthy BV, Laštovička J, Qian L (2013) Evidence of long-term change in zonal wind in the tropical lower mesosphere: observations and model simulations. Geophys Res Lett 40:397-401, doi: 10.1002/grl.50158

Reinsel GC, Miller AJ, Weatherhead EC, Flynn LE, Nagatani RM, Tiao GC, Wuebbles DJ (2005) Trend analysis of total ozone data for turnaround and dynamical contributions. J Geophys Res 110:D16306, doi: 10.1029/2004JD004662

Remsberg EE (2009) Trends and solar cycle effects in temperatures versus altitude from the Halogen Occultation Experiment for the mesosphere and upper stratosphere. J Geophys Res 114:D12303, doi: 10.1029/2009JD011897

Remsberg EE (2010) Observed seasonal to decadal scale responses in mesospheric water vapor. J Geophys Res 115:D06306, doi: 10.1029/ 2009JD012904

Rishbeth H (1990) A greenhouse effect in the ionosphere? Planet Space Sci 38:945-948

Rishbeth H, Roble RG (1992) Cooling of the upper atmosphere by enhanced greenhouse gases - modeling of thermospheric and ionospheric effects. Planet Space Sci 40:1011-1026

Roble RG, Dickinson DE RE (1989) How will changes in carbon dioxide and methane modify the mean structure of the mesosphere and lower thermosphere? Geophys Res Lett 16:1441-1444

Rong PP, Russell JM III, Hervig ME, Bailey SM (2012) The roles of temperature and water vapor at different stages of the polar mesospheric cloud season. J Geophys Res 117:D04208, doi: 10.1029/2011JD016464

Scott TJ, Stamper R, Rishbeth H (2014) Long-term changes in thermospheric composition inferred from a spectral analysis of ionospheric F-region data. Ann Geophys 32:113-119, www.ann-geophys.net/32/114/2014/ 
She C-Y, Krueger DA, Akmaev R, Schmidt H, Talaat E, Yee S (2009) Long-term variability in mesopause region temperatures over Fort Collins, Colorado (41 $\hat{A}^{0} \mathrm{~N}, 105 \hat{A}^{0} W$ ) based on lidar observations from 1990 through 2007. J Atmos Solar-Terr Phys 71:1558-1564, doi: 10.1016/j.jastp.2009.05.007

Shettle PE, DeLand MT, Thomas GE, Olivero JJ (2009) Long term variations in the frequency of polar mesospheric clouds in the Northern Hemisphere from SBUV. Geophys Res Lett 36:L02803, doi: 10.1029/2008GL036048

Siskind DE, Stevens MH, Hervig ME, Randall CE (2013) Recent observations of high mass density polar mesospheric clouds: a link to space traffic? Geophys Res Lett 40:2813-2817, doi: 10.1002/grl.50540

Smith AK, Garcia RR, Marsh DR, Kinnison DE, Richter JH (2010) Simulations of the response of mesospheric circulation and temperature to the Antarctic ozone hole. Geophys Res Lett 37:L22803, doi: 10.1029/2010GL045255

Solomon S, Rosenlof KH, Portmann RW, Daniel JS, Davis SM, Sanford TJ, Plattner G-K (2010a) Contributions of stratospheric water vapor to decadal changes in the rate of global warming. Science 327:1219-1223

Solomon SC, Woods TN, Didkovski LV, Emmert JT, Qian L (2010b) Anomalously low solar extreme-ultraviolet irradiance and thermospheric density during solar minimum. Geophys Res Lett 37:L16103, doi: 10.1029/2010GL044468

Solomon SC, Qian L, Burns AG (2013) The anomalous ionosphere between solar cycles 23 and 24. J Geophys Res 118:6524-6535, doi: 10.1002/jgra.50561

Sonnemann GR, Hartogh P, Berger U, Lübken F-J, Grygalashvyly M (2012) Anthropogenic effects on the distribution of minor chemical constituents in the mesosphere/lower thermosphere - a model study. Adv Space Res 50:598-618

Sridharan S, Prasanth PV, Kumar YB (2009) A report on long term trends and variabilities in middle atmospheric temperature over Gadanki $\left(13.5^{\circ} \mathrm{N}, 79.2^{\circ} \mathrm{E}\right)$. J Atmos Solar-Terr Phys 71, doi: 10.1016/j.jastp.2008.09.017

Stiller GP, von Clarmann T, Haenel F, Funke B, Glatthor N, Grabowski U, Kellmann S, Kiefer M, Linden A, Lossow S, Lopez-Puertas M (2012) Observed temporal evolution of global mean age of stratospheric air for the 2002 to 2010 period. Atmos Chem Phys 12:3311-3331, www.atmos-chem-phys.net/12/ $3311 / 2012 /$

Sunda S, Vyas BM, Khekale PV (2013) Storm time spatial variations in TEC during moderate geomagnetic storms in extremely low solar activity conditions (2007-2009) over Indian region. Adv Space Res 52:158-176, http://dx.doi.org/ 10.1016/j.asr.2013.03.006

Tsuda T, Rao NV, Riggin D, Gurubaran S, Reid LM, Vincent RA (2013) Long-term variability of the mean winds in the mesosphere and lower thermosphere (MLT) observed with radars in the tropics. Paper presented at International CAWSES-II Symposium, Nagoya

Verkhoglyadova OP, Tsurutani BT, Mannucci AJ, Mlynczak MG, Hunt LA, Runge T (2013) Variability of ionospheric TEC during solar and geomagnetic minima (2008 and 2009): external high speed stream drivers. Ann Geophys 31:263-276

Walsh PL, Oliver WL (2011) Is thermospheric long-term cooling due to CO2 or O3? Ann Geophys 29:1779-1782, doi: 10.5194/angeo-29-1779-2011

Weatherhead EC, Reinsel GC, Tiao GC, Jackman CH, Bishop L, Hollandsworth Frith SM, DeLuisi J, Keller T, Oltmans SJ, Fleming EL, Wuebbles DJ, Kerr JB, Miller AJ, Herman J, McPeters R, Nagatani RM, Frederick JE (2000) Detecting the recovery of total column ozone. J Geophys Res 105:22201-22210

Zhang S-R, Holt J (2013) Long-term ionospheric cooling: dependency on local time, season, solar activity, and geomagnetic activity. J Geophys Res 118:3719-3730, doi: 10.1002/jgra.50306

Zhang S-R, Holt J, Kurdzo J (2011) Millstone Hill ISR observations of uppe atmospheric long-term changes: height dependency. J Geophys Res 116:A00H05, doi:10.1029/2010JA016414

doi:10.1186/s40645-014-0021-6

Cite this article as: Laštovička et al:: Response of the mesospherethermosphere-ionosphere system to global change - CAWSES-II contribution. Progress in Earth and Planetary Science 2014 1:21.

\section{Submit your manuscript to a SpringerOpen ${ }^{\circ}$ journal and benefit from:}

- Convenient online submission

- Rigorous peer review

- Immediate publication on acceptance

- Open access: articles freely available online

- High visibility within the field

- Retaining the copyright to your article

Submit your next manuscript at $\gg$ springeropen.com 